Florida International University

FIU Digital Commons

8-2-1996

\title{
The effect of group counseling on the self-esteem, attendance, and counselor utilization of inmigrant hispanic limited english proficient secondary students
}

Ivette Armand Covert

Florida International University

DOI: $10.25148 /$ etd.FI14061531

Follow this and additional works at: https:// digitalcommons.fiu.edu/etd

Part of the Adult and Continuing Education Administration Commons, and the Higher Education Commons

\section{Recommended Citation}

Covert, Ivette Armand, "The effect of group counseling on the self-esteem, attendance, and counselor utilization of inmigrant hispanic limited english proficient secondary students" (1996). FIU Electronic Theses and Dissertations. 2661.

https://digitalcommons.fiu.edu/etd/2661 


\section{FLORIDA INTERNATIONAL UNIVERSITY \\ Miami, Florida}

THE EFFECT OF GROUP COUNSELING ON THE SELF-ESTEEM, ATTENDANCE, AND COUNSELOR UTILIZATION OF IMMIGRANT HISPANIC LIMITED ENGLISH PROFICIENT SECONDARY STUDENTS

A dissertation submitted in partial satisfaction of the

requirements for the degree of

DOCTOR OF EDUCATION

IN

ADULT EDUCATION AND HUMAN RESOURCE DEVELOPMENT

by

Yvette Armand Covert 
To: Dear I. Ira Goldenberg, College of Education

This dissertation, written by Yvette Armand Covert, and entitled The Effect of Group Counseling on the Self-Esteem, Attendance, and Counselor Utilization of Immigrant Hispanic Limited English Proficient Secondary Students, having been approved in respect to style and intellectual content, is referred to you for your judgment.

We have read this dissertation and recommend that it be approved.

\author{
Rosa Castro Feinberg
}

Lorraine Gay, Co-Major Professor

Douglas H. Smith, Co-Major Professor

Date of Defense: August 2, 1996

The dissertation of Yvette Armand Covert is approved.

Dean I. Ira Goldenberg College of Education

Dr. Richard L. Campbell

Dean of Graduate Studies

Florida International University 
${ }^{\circ}$ COPYRIGHT 1996 by Yvette Armand Covert

All rights reserved 
This dissertation is dedicated to my mother and father, Yvette and Raul Armand whose love and encouragement to be the best at whatever I did, provided inspiration and support and to Nelly Fresneda, my aunt and second mother, who has always been there for me. 


\section{ACKNOWLEDGMENTS}

This work was made possible by my committee members, colleagues, friends and family. To my committee chairman, Dr. Douglas H. Smith, a sincere thank you for your guidance, perseverance and encouragement from the beginning to the end of my doctoral studies. To my committee co-chairperson, Dr. Lorraine Gay, my sincere appreciation for arousing my interest in bilingual education research and helping me with the problem and research aspect of this study. I would like to give special, well-deserved thanks to Dr. Rosa Castro Feinberg for sharing her wisdom and knowledge regarding limited-English proficient students. Thank you for your thoroughness and promptness, they kept me focused and on task.

This work reflects 10 years of dedication to counseling and the education of limited English proficient students. In the field of counseling I must express my sincere gratitude to Maurine Harrison for giving me the chance to discover and succeed in a new field; Emilio Gonzalez, my counseling coach, for sharing his knowledge with me; and George Phelan for being my guiding light in this phase of my life. To my colleagues Ernie Arill and Melanie Bailey for being part of the school-wide effort to provide counseling services for the LEP population.

I would like to thank Lilia Fernandez, Sandra Gutierrez, and Maria Pabellon, my N.A.B.E. partners and friends. Their words of support, confidence and encouragement through the years convinced me not to quit. A well deserved thanks to Georgina Palomo 
for giving me the initial opportunity to work with limited English proficient students and for sharing my concern for the services they received.

Throughout the dissertation process Delia Garcia and Wayne Muller were of invaluable assistance. We shared the exhilaration and frustration of the writing process. I must thank Delia for sharing ideas and Wayne for his help on the computer. To my colleague and friend, Connie Navarro, thanks for making me aware of my knowledge and skills in a very short time.

I must thank two people without whom this study would not have been possible. First is Dr. James Battle, the author of the CFSEI utilized in this study, for his constant support and assistance with the statistical analysis. Second is Mr. Dennis Davis, my mentor, principal and friend, for being a role model, a supporter, and a master teacher. His wisdom, patience, respect and love of education have made a difference in my life, personally and professionally.

To my husband and children my deepest gratitude for their unconditional love and endurance. They never questioned the endless hours on the computer or in the library. They tolerated the paper piles and my inability to do many "mom" things on many occasions. Thank you for being so understanding for so long.

I acknowledge my gratitude, my debts and my affection to all mentioned and many more. 


\author{
ABSTRACT OF THE DISSERTATION \\ THE EFFECT OF GROUP COUNSELING \\ ON THE SELF-ESTEEM, ATTENDANCE, AND COUNSELOR \\ UTILIZATION OF IMMIGRANT HISPANIC SECONDARY \\ LIMITED ENGLISH PROFICIENT STUDENTS \\ by \\ Yvette A. Covert \\ Florida International University, 1996 \\ Professor Douglas Smith, Major Professor
}

As the population of the United States becomes more diverse and the immigrant Hispanic, limited English proficient (LEP) school age population continues to grow, understanding and addressing the needs of these students becomes a pressing question. The purpose of this study was to investigate the effects of group counseling, by a bilingual counselor, on the selfesteem, attendance and counselor utilization of Hispanic LEP high school students. The design for this study was a quasi-experimental design. The experimental and control groups consisted of one class from each of the four levels of English for Speakers of Other Languages (ESOL), I-IV. The counseling intervention, the independent variable, was delivered by a bilingual counselor once a week, for fifteen weeks.

A total of 112 immigrant Hispanic LEP students selected from the total ESOL student population participated in the study. The experimental and control groups were administered 
the Culture Free Self Esteem Inventory (CFSEI) Form AD as a pretest and posttest. The Background Information Questionnaire (BIQ) was utilized to gather information on counselor utilization and demographic data. Attendance data were obtained from the students' computer records. At the conclusion of the study the differences between the experimental and control groups on the three dependent variables were compared.

Statistical analyses of the data were done using SPSS statistical software. A multivariate analysis of variance (MANOVA) was utilized to determine if there were significant differences in the self-esteem scores, attendance and counselor utilization. Correlational analyses was utilized to determine if there was a relationship between English language proficiency and self-esteem and between acculturation level and self-esteem.

The study results indicate that there were no significant differences in the self-esteem scores and attendance of the subjects in the experimental group at the completion of the group counseling treatment. Counselor utilization was statistically significant for the targeted population. A relationship was found between English language proficiency level and self-esteem scores for students in ESOL levels II, III and IV. No significant correlation was found between acculturation and self-esteem.

Research on the dropout rates of LEP coupled with the results of this study show that students at the intermediate and advanced levels of ESOL (III and IV) exhibit more positive self-esteem and achieve higher graduation rates that levels I and II. LEP students at levels I and II, once they became familiar with the role and function of school counselors through group counseling, utilized their services. 


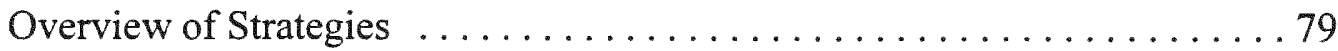

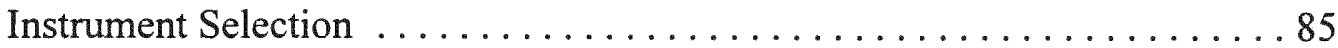

Background Information Questionnaire .............. 85

Culture Free Self-Esteem Inventory Form AD ............ 85

The Short Acculturation Scale for Hispanic Youth (SASH-Y) . . . . . . 87

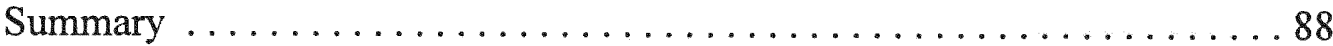

IV. ANALYSIS OF THE DATA ........................... 89

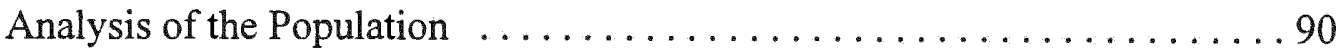

Methodology ................................. 90

Specific Research Questions .......................... 91

Relationship of English Language Proficiency Level and

Acculturation to Self-Esteem . . . . . . . . . . . . . . . . . . 97

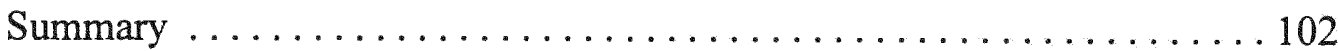

V. CONCLUSIONS AND RECOMMENDATIONS $\ldots \ldots \ldots \ldots \ldots \ldots \ldots . \ldots 103$

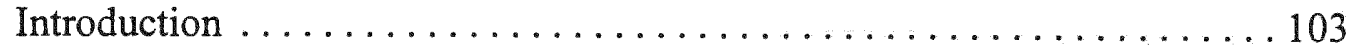

Summary of the Study ......................... 103

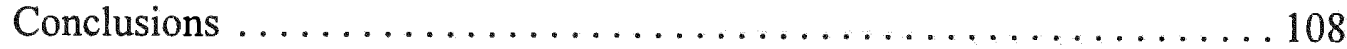

Recommendations for Further Research . . . . . . . . . . . . 110

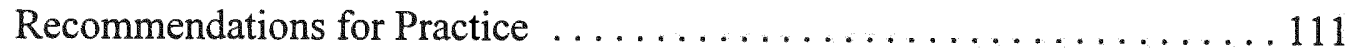

Conclusion ............................... 112

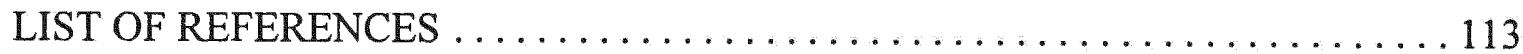

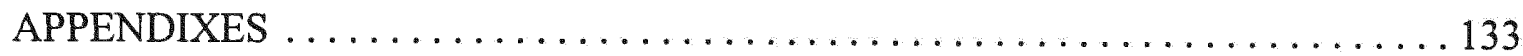

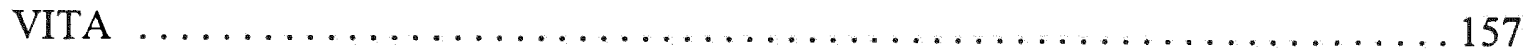




\section{LIST OF TABLES}

TABLE

PAGE

$1 \quad$ Limited English Proficient Population by Language Group ............ 31

2 Potential Dropout Indicators and Risk Factors $\ldots \ldots \ldots \ldots \ldots \ldots \ldots$

3 Erikson's Life-Cycle Tasks and Virtues Arredondo's Issues for Immigrants . . 48

$4 \quad$ Means of Population by Countries . . . . . . . . . . . . . . . . . . 75

5 Multivariate Analyses of Variance for Self-Esteem, Attendance and Counselor Utilization . . . . . . . . . . . . . . . . . . . 92

6 Comparison of Mean Scores on the Culture Free Self-Esteem Inventory

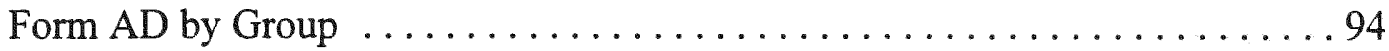

7 Comparison of Means for Counselor Utilization by Group . . . . . . . . . . 97

8 Means of Counselor Utilization by Level of English for Speakers of Other Languages . . . . . . . . . . . . . . . . . 98

9 Correlation of CFSEI-AD Self-Esteem Scores and ESOL . . . . . . . . . . 99

10 Total Self-Esteem Means by Levels of ESOL . . . . . . . . . . . . . . 100

11 Correlation of SASH-Y Scores with CFSEI-AD Self-Esteem Scores . . . . . . 101

12 Comparison of Means of Pretest and Posttests Self-Esteem Scores for the Non-Study Group . . . . . . . . . . . . . . . . . . . 135 


\section{Chapter I}

\section{Background of the Problem}

As the population of the United States becomes more diverse and the language minority school-age population continues to grow, understanding the needs of language minority students will become an increasingly pressing question. Language minority students refers to those whose home language is other than English; some are proficient in English while others are not (OBEMLA, 1992). School systems across the nation face the challenge of educating and graduating increasing numbers of non-English and limited-English proficient (LEP) students. Since the 1970s, federal and state laws have mandated that programs and services meet the educational needs of LEP students (August, Hakuta, \& Pompa, 1994). School district implementation of these mandates focus primarily on elementary schools, where the largest numbers of LEP students are enrolled, leaving a gap in the services provided to adolescents and young adults at the high school level (Lucas, 1993; Lucas, Henze, \& Donato, 1990).

One of the President's National Education Goals in America 2000 (1991) is to improve the graduation rate to at least $90 \%$, and to close the gap in high school graduation rates between American students from minority backgrounds and their nonminority counterparts (Grannis, 1991). For a student population that is becoming more diverse the six goals of America 2000 seem almost unattainable (Fenelon, Khoxayo, Kwiat, \& Rodriguez, 1993). 


\section{Demographic Data}

The language minority population of the United States is growing at a rapid rate. The Spanish speaking population, who are language minority students by definition, for example, increased by 53\% between 1980 and 1990 (U. S. Department of Commerce, Bureau of the Census, 1991b) while the total U. S. population increased by $9 \%$ during the same period (Chapa \& Valencia, 1993). "About half of this growth was due to foreign immigration and half was due to births to Latinos (Spanish speaking persons) in the United States" (Chapa \& Valencia, 1993). Based on Census data, Rong and PreissleGoetz (1990) report that between 900,000 and 1,100,000 legal and illegal immigrants enter the United States annually.

Hispanics experience higher dropout rates, lower representation in college preparatory classes, lower rates of college enrollment, and fewer years of school completion than their non-Hispanic white counterparts (Lewis, 1994). A study done using data from the 1990 Bureau of the Census found that the overall dropout rate for 16to 24 -year old Hispanics was $30 \%$, compared with $18 \%$ for non-Hispanic blacks and $10 \%$ for non-Hispanic whites (U. S. General Accounting Office (GAO), 1994). National dropout rates for Hispanics range from $26 \%$ to $40 \%$ (Arias, 1986; Nicolau \& Ramos, 1990; Velez, 1989). Within the Hispanic population, those born outside the United States who are recent immigrants exhibit an even higher dropout rate, (43\%) than the U.S. born Hispanics (20\%) (U. S. GAO, 1994). 
In 1990 , the total language minority population was approximately $14 \%$ of the students ages 5-17. Of those language minority students, $62.2 \%$ spoke English well and 37.8\% were limited English proficient (LEP) (Educational Research Service, 1995). Based on the definition of language minority and the above referenced statistics it is necessary to clarify that not all language minority students are LEP, but all LEP students are language minorities. The LEP population increased $12.6 \%$ in one year between 1991 1992 and 1992-1993 while the overall student population increased by $1.02 \%$ (NCBE, 1995). In 1991, LEP students comprised $6 \%$, or one out of every 20 students, of a public school population of roughly 40 million (OBEMLA, 1992). In Florida between 19891990 and 1990-1991, the number of limited English proficient students increased by 35.9\%. In Dade County, Florida LEP students make up 13\% of the total student population (NCBE, 1995).

High school students speaking little or no English pose a challenge to educators. They must educate and graduate this growing population in spite of escalating dropout rates for language minority students. A study by Fleischman and Hopstock (1993), where they surveyed 745 school districts during the 1991-92 school year, revealed that the Spanish-speaking group (Hispanics) represented $72.9 \%$ of the total LEP population.

There is a lack of definitive data on the number of LEP students who drop out since the definition of LEP varies from state to state. However, a 1995 report by the Educational Research Service states that, "among persons who reported having difficulty speaking English, 42\% had dropped out of school" (Educational Research Service, 1995, 
p. 32). A longitudinal study of LEP high school students done in Alberta, Canada from 1988-1993 found that $74 \%$ of the students dropped out before graduation (Watt \& Roessingh, 1994). One of the findings of the study done by the General Accounting Office (1994) was that recent immigrants to the United States who spoke English "not well" or "not at all" experienced dropout rates three times the rate of those who spoke English "well."

Dade County Public Schools (DCPS) in Miami, Florida conducts a cross-sectional analysis of student dropouts annually. The total student enrollment for the district mirrors the County's diverse ethnic population. During the 1994-1995 school year, DCPS had an enrollment of 321,955 students in the k-12 program, of which $15.1 \%$ were white nonHispanic, 34.2\% Black non-Hispanic, 49.4\% Hispanic and 1.3\% Asian and Native American. Minorities, mainly African Americans and Hispanics, comprise the majority of the student population. While the dropout rate for grades $9-12$ increased from $7.4 \%$ in 1990-91 to $9.1 \%$ in 1992-93, the dropout rates for African Americans and Hispanics of $10.6 \%$ and $8.7 \%$ respectively, surpassed the rate for White, Non-Hispanics of $8.0 \%$ (DCPS, 1994).

\section{Dropout Issues}

During the past decade, educational efforts focused on dropout prevention programs designed to provide early identification, prevention, and intervention for students at risk of dropping out. Research indicates that signs of dropping out of school may be visible as early as elementary school, so early identification provides educators 
with more time to intervene with these students (Rumberger, 1987; Steinberg, 1984). More recent literature cite other risk factors for dropping out: family and peer influences, academic performance, school behaviors (attendance, discipline) use of illegal substances, attitudes and behaviors of teachers and other school staff (Bull, 1991; U.S. GAO, 1994). Research done to determine why students drop out indicates that dropping out can be correlated to race or ethnicity, gender, marriage at a young age, parents' education, socioeconomic status and retention in the same grade (Larsen \& Shertzer, 1987).

For language minorities, factors linked to dropping out include fluency in English, age at immigration, prejudices against immigrant minorities, teacher attitudes and expectations, acculturation, low self-esteem and the loss of a sense of identity (Rong, 1990). Parents' level of education, family structure, future employment opportunities, school attendance and academic achievement have also been cited as reasons for language minority students leaving school (Reyes \& Jason, 1993). Four factors commonly cited for Hispanic language minority students for which data were available from the 1990 census are: (a) not born in the United States, (b) lack of English-speaking ability, (c) low family income, and (d) marriage and childbirth (U.S. GAO, 1994)

Foreign-born Hispanics who immigrate to the United States are the groups most likely to be undereducated, not enrolled in school and do not complete a high school education (Waggoner, 1991). According to Waggoner (1991) foreign-born Hispanics almost always live in homes in which a language other than English is spoken, 
presumably Spanish. Additionally, Waggoner (1991) states that foreign-born Hispanics have lower levels of schooling and "are more likely to be from families with incomes below the poverty level than native-born Hispanics" (p. 121).

Fluency or competency in English may be related to dropout rates for Hispanics. According to Gringas and Careaga (1989), "high competence in English leads to good academic performance which, in turn, leads to lower dropout rates" (p. 3). Besides competency in English, a myriad of personal, social, cultural, and affective factors impact the performance in school of LEP students. Personal reasons include pregnancy, marriage, employment, and "not liking school." Social and cultural reasons include "not getting along with teachers," ridicule, and rejection by peers of the majority culture, alienation from the dominant society, and being judged by lower standards because of teachers' expectations. Affective factors include a perceived sense of worthlessness or helplessness, low self-esteem, role confusion, and high levels of anxiety (Gringas \& Careaga, 1989). Research done by Strassburger et al. (1990), to explore factors associated with the discrepancy in achievement between Hispanics and Anglo students, found that self-esteem had a larger main effect on the student's grade point average than socioeconomic level. Coping with such conflicts leads to isolation, passivity, withdrawal, truancy and hostility.

\section{Intervention Strategies}

The rapid growth of the Hispanic LEP populations and the high dropout rates they exhibit are forcing educators to reexamine and redefine current practices. 
Comprehensive prevention and intervention programs to address the increasing number of students who are not completing a high school education include tutorial programs, curricular adaptations, counseling, and work related approaches (NCBE, 1989; Gingras, 1989). Providing additional help to students through tutoring and Bilingual Curriculum Content $(\mathrm{BCC})$ area instruction are strategies used to address the academic needs of LEP students. However, the personal and social problems need to be addressed by school counselors. Counseling intervention strategies for these "at risk" students include individual and small group counseling, increased parental involvement, and participation in a self-esteem program (Walker, 1991).

Individual, small-group counseling and classroom group guidance are the three components of direct services in a comprehensive school counseling program. Individual counseling has been rated by high school teachers as the most important responsibility of counselors (Gibson, 1990). Small-group counseling is cost and time effective allowing students with similar problems to share coping strategies, receive feedback, and challenge each other to make changes (Borders \& Drury, 1992). Classroom group guidance can address the needs of all students (Myrick, 1987) through the use of structured units based on the developmental needs and interests of students at a particular level (Borders \& Drury, 1992). Group counseling has proven effective to improve academic achievement (Deffenbacher \& Kemper, 1974; Morese, 1987), school attendance (Krivatsy-O'Hara, Reed \& Davenport, 1978), self-esteem (Herr, 1982), and self concepts (Cangelosi, Gressard, \& Mines, 1980). 
As working with minorities becomes the norm rather than the exception, counselors must become better able to meet the cultural and affective needs of the students they work with. According to Sue (1991) the diversification trend will require that (a) counselor education programs recruit minority group trainees, (b) counselors be trained to work with culturally diverse clients, and (c) counselors intervene with methods found to be effective with ethnic/racial minorities.

Counselors, like teachers, need to deliver culturally appropriate services to this diverse population who traditionally underutilize counseling services (Casas \& Vasquez, 1990). "Evidence continues to accumulate, for instance, that economically and educationally disadvantaged clients may not be oriented toward talk therapies, that selfdisclosure in counseling may be incompatible with cultural values of Asian Americans, Latinos, and American Indians, that the sociopolitical atmosphere may dictate against working openly with the counselor, and that some minority clients may benefit more from the counselor's active intervention in the system" (Sue, 1992, p.14). Pedersen, Fukuyama and Heath (1990) summarize the counselor's task to be able to "effectively adapt the skills of traditional counseling to the perspectives of culturally different clients. Genuineness, warmth, and empathy can and must be demonstrated differently in different cultural settings" (p. 31).

More than teachers or administrators, the school counselor is in a key position to intervene between the limited-English speaking (LEP) student and the school, the family, and the community (Keyes, 1989). Counselors are uniquely trained to provide 
interventions that focus on improving the self-esteem and motivation of students (Braught, S.; Lewis, 1993). The counselor needs to be sensitive to the unique problems LEP students encounter such as language barriers, cultural conflicts, ethnic identity, and low self-esteem (Sanchez, 1981; Pedersen, 1989). Cranstron-Gringras \& Anderson as quoted in Toffoli and Allan (1992) clarify the dual problem that LEP students face: the need to learn how to communicate and the need to acquire the knowledge, understanding and skills to function effectively in a new culture. In a review of the literature Toffoli and Allan (1992) cite Parkes (1971) as suggesting that counseling "which exists to help people change aspects of their assumptive worlds, can help them open this internal world for introspection, so that old assumptions can be examined and questioned and new ones can be rehearsed" (p. 137). Toffoli and Allan (1992) responded by creating a group guidance program for secondary LEP students using guided imagery, drawing, and writing to address the conflict of living in two cultures, the desire to keep their cultural heritage alive and to have feelings validated.

This state of affairs poses a number of critical questions: Can the growing numbers of Hispanic LEP students who are dropping out of high school continue to be ignored? Are school counselors utilizing their skills to meet the personal, social, cultural, and affective needs of LEP students? Are counselors aware of the esteem needs of culturally diverse clients? What interventions are counselors utilizing to help LEP students achieve high school graduation? 
This study will examine some aspects of these questions for a selected population of immigrant Hispanic LEP high school students.

\section{Statement of the Problem}

Immigrant Hispanic students who are proficient in English fail to achieve basic levels of performance, while those who are LEP fail at much higher rates (OBEMLA, 1992; U.S. GAO, 1994). Demographic trends leading to a high growth rate in the number of persons in the U.S. who speak a language other than English coupled with the disproportionately high dropout rates for Hispanics warrant an investigation of variables related to their school performance.

Personal, social, school, cultural, and affective problems of the immigrant Hispanic LEP population are unique from a counseling perspective. Dropout literature identifies characteristics that "at risk" students have in common such as: health problems, financial distress, low parental expectations, difficulty in relating to authority figures low socioeconomic status, having been retained in the same grade at least once, excessive absences, poor grades, and limited extracurricular involvement (Gringas \& Careaga, 1989; NCBE Forum, 1989; Rong, 1990). For language minorities other factors include fluency in English, language of the family, age at immigration (Jones, 1985; Rumberger, 1987; Steinberg, 1984), prejudices against immigrant minorities (Suarez-Orozco, 1987), place of birth (McCarthy, 1985), school environment and programmatic factors, language of instruction, teacher attitudes, and expectations (Ochoa, 1987). 
The research literature does not provide an adequate account of intervention strategies to use with "at risk," immigrant Hispanic limited English proficient (LEP) secondary students. A thorough review of the counseling and limited English proficient literature revealed that Toffoli and Allan's (1992) study of group counseling for LEP secondary students in Canada is one of a kind. Therefore, the problem to be addressed by this study is the effect of group counseling on the self-esteem, attendance and counselor utilization of immigrant, Hispanic LEP high school students. The group counseling will be delivered by a bilingual (English/Spanish) counselor on a weekly basis to designated groups of students in their English for Speakers of Other Languages (ESOL) classes. The topics and affective education areas to be covered are further discussed in Chapter III.

\section{Purpose of the Study}

The basic research question to be addressed by this study is: What is the effect of a group counseling program, delivered by a bilingual counselor, on the performance in school of immigrant Hispanic limited English proficient (LEP) secondary students? To address the basic research question three specific research questions comprise the core of this study:

1) What is the effect of group counseling on the total, general, social, and personal self-esteem of immigrant Hispanic LEP secondary students as determined by the Culture Free Self Esteem Inventory?

2) What is the effect of group counseling on the attendance of immigrant Hispanic LEP secondary students? 
3) What is the effect of a group counseling component on the counselor utilization of immigrant Hispanic LEP secondary students?

Two related research questions will be addressed:

1) To what extent are differences in English language proficiency related to selfesteem?

2) To what extent is acculturation level as measured by the Short Acculturation Scale for Hispanic Youth (SASH-Y) related to self-esteem?

\section{Conceptual Framework}

Limited English proficient (LEP) students can be immigrants or newcomers to this nation or they may be born in the United States in families that primarily speak the language of the parents' country of origin. According to Rong (1990), there are three categories to consider: (a) natives--American-born children with two American-born parents; (b) children of immigrants--American-born children with one or two foreignborn parent(s); (c) immigrants--foreign born. Children of immigrants and immigrants are often combined and referred to as language minority students when English is not their primary language (Rong, 1990).

Immigration is a major life upheaval that creates a sense of disequilibrium. The loss of a sense of identity and belonging as one faces new personal, societal, economic, and political stressors can be overwhelming. To compound the struggle of the immigrant, there are racial, ethnic, and cultural differences with the majority culture that impact the functioning of the individual. Under these circumstances, the individual's self-image and 
self-esteem waivers as he or she attempts to care for himself and others in a new environment (Arredondo, 1986).

The underachievement and high dropout rates of Hispanic LEP students at all educational levels forces educators and counselors to identify, develop, and implement innovative techniques to improve the social, psychological, and academic performance of students. Investigating the effects of counselor intervention on self-esteem, attendance, and counselor utilization of immigrant Hispanic LEP students, who are targeted as potential dropouts, is relevant for educational institutions concerned with improving the achievement and performance of this growing population because acculturation and selfesteem are identified as factors impacting the school achievement of language minority students (Gringas \& Careaga, 1989; Pedersen, 1990; Sanchez, 1981; Strassburger, 1990; Sue, 1990).

Studies focusing on acculturation have become prominent as the demographics of the United States continue to become more culturally diverse (Sue, 1990). Acculturation is a process involving a change in the behavior and attitudes of members of minority individuals toward those of the dominant or host society (Rogler, Cortes \& Malgady, 1991). It has been defined as "change of cultural patterns to those of the host society" (Gordon, 1978, p. 169) and as "the acquisition of values of a host society by members of a minority or immigrant group" (Garcia \& Lega, 1979, p. 247). Szapocznik and Kurtines (1980) define acculturation as a process whereby cultural characteristics are relinquished 
or retained. Acculturation can be bicultural in context when there is community support for the ethnic minority as well as a dominant majority culture.

In a study with language minority students in Canada, Clement (as cited in Negy \& Woods, 1992), found a relationship between acculturation and self-esteem or selfconfidence. Their study also revealed that self-esteem or self-confidence had "the strongest association with proficiency in English as a second language and acculturation" (Negy \& Woods, 1992).

Although acculturation is rarely defined in terms of changes within the dominant majority towards the minority culture, Berry (1980) stated that change can occur in the dominant culture as well as in the minority culture. Similarly, three options of acculturation or adaptation emerged in studies by Sodowsky and Plake (1991). First is assimilation, which means relinquishing one's culture to become more like the dominant culture, second is integration, whereby one maintains the original culture but integrates into the majority culture, and last is rejection, where the U.S. culture is distant and an ethnic group enclave is established. Asian and Hispanics, unlike their early European counterparts, are not easily assimilated into the majority culture (Sue, 1992).

Studies of acculturation as it relates to counseling reveal that a client's level or degree of acculturation into the dominant society can influence the problems of Hispanic clients, the level of stress, and the way the problems are interpreted (Sue, 1990). Acculturation can also affect the perceptions and responses to counseling (Sue, 1990) and thus the overall effectiveness of counseling (Cuellar, Harris, \& Jasson, 1980). 
Participation in counseling has also proven to be dependent on the client's level of acculturation (Sodowsky, Lai \& Plake, 1991). Additionally, studying acculturation helps in understanding the stresses of minority clients (Lang, Munoz, Bernal \& Sorensen, 1982).

Self-esteem is a fundamental human need (Branden, 1990). Definitions of selfesteem vary in depth and scope. It refers to feelings of personal worth and the level of satisfaction with one's self. Walz (1991) defines self-esteem as having a positive attitude, valuing ourselves highly, and being convinced that we are competent, powerful and in control of our lives. It helps us compare ourselves favorably with others. According to Branden (1992) self-esteem is (a) confidence in our ability to think, (b) confidence in our ability to cope with the challenges of life, (c) confidence in our right to be happy, and (d) feeling of being worthy, deserving, and entitled to assert our needs and wants and to enjoy the fruits of our effort.

The importance of self-esteem as it relates to success and achievement in school cannot be underestimated. Having high self-esteem can empower, energize and motivate an individual. It enables one to make independent decisions, take risks, become immune to rejections and disappointments, and act on our own initiative. It helps to cope with challenges and to believe that one can achieve what they need and want (Walz, 1991). Researchers of youth and adults have identified what causes low and high selfesteem, which in turn affects behavior. Among the determinants for low self-esteem are domination, rejection, severe punishment, and fewer experiences of love (Branden, 1992). 
High self-esteem is associated with the family interaction, high parental self-esteem, and school climate (Task Force to Promote Self-Esteem, 1990). Research indicates that characteristics such as security, competence, connectedness, uniqueness, assertiveness, and spirituality are generic to the development of self-esteem. A person's perception of self-worth once established, tends to be fairly stable and resistant to change (Battle, 1990).

Identity is another important issue for immigrants. The losses experienced by those who leave their homeland negatively affect their sense of identity. There is loss of family members in the separation, loss of autonomy due to lack of language, loss of group and social identity as a result of a strange culture, and a loss of belonging evolving from feelings of rejections, embarrassment, and depersonalization (Chavira \& Phinney, 1991; Friedlander, 1991).

Adolescence, as a developmental stage of the life cycle, is plagued with physical, social, emotional and behavioral changes. In itself it is a transitional period filled with turmoil and conflict. For the immigrant non-English or limited-English speaking adolescent, entering a secondary school in the United States can be a traumatic experience.

As the language minority, specifically the immigrant, Hispanic limited English proficient (LEP) population increases, so do their needs for an equal education. Educators and counselors must identify, develop, and implement innovative techniques to address their needs in order to improve the academic performance of these students. 
Investigating how the role of bilingual counselors can impact the performance of immigrant Hispanic LEP students targeted as potential dropouts, is essential for educational institutions concerned with improving the achievement and success of Hispanic students.

\section{Significance of the Study}

A premise of this study is that addressing the personal, social, and cultural needs of immigrant Hispanic LEP secondary students through a group counseling component delivered by a bilingual counselor will enhance their self-esteem, attendance, and counselor use. A group counseling program is a proactive measure to initially familiarize LEP students with the role and function of school counselors at the high school level. Utilizing bilingual counselors will improve communication in the facilitative relationship of counselor and student. The relationship, or bond, will enable the students to: (a) understand what services counselors provide (b) lessen their anxieties by being able to discuss their fears and apprehension, (c) identify with culturally similar role models within the school, and (d) understand and diminish the personal, social, and cultural conflicts they are experiencing.

Results of this study will have a two pronged effect. First, it will contribute to the research on immigrant Hispanic secondary limited English proficient (LEP) students who are at risk of dropping out of high school. Second, it will augment the multicultural counseling literature by clarifying the role and impact that bilingual counselors can have on the performance of LEP students in secondary schools. 
Results and findings from this study will contribute empirical evidence to the dropout and counseling literature of Hispanics in the Southeastern United States versus the primarily Mexican population in the Southwestern United States.

\section{Definition of Terms}

The definitions of the following terms are intended to facilitate understanding the purpose and parameters of this study.

Language minority student: those individuals whose family or home language is other than English; a part of this population is English proficient and another part is not (OBEMLA, 1992).

Limited English proficient (LEP): (a) individuals who were not born in the United States or whose native language is a language other than English; (b) individuals who come from environments where a language other than English is dominant; (c) individuals who are American Indian and Alaska Natives and who come from environments where a language other than English has had a significant impact on their level of English language proficiency; and who, by reason thereof, have sufficient difficulty speaking, reading, writing, or understanding the English language to deny such individuals the opportunity to learn successfully in classrooms where the language of instruction is English or to participate fully in our society (OBEMLA, 1992).

Self-Esteem: having a positive attitude, valuing ourselves highly, and being convinced that we are competent, powerful and in control of our lives (Walz, 1991). Branden's definition (as cited in Battle, 1990) of self-esteem has two interrelated aspects: 
1. Each ESOL class level has attained a different level of mastery of the English language

2. Counseling intervention will be reasonably similar for the ESOL classes receiving treatment.

3. Students seek counseling assistance for personal, social and esteem problems.

4. School life presents no greater causes for students to seek out counselors in the spring semester more than in the fall semester.

\section{Delimitations}

The following three delimitations apply to this study:

1. This study is limited to a single suburban high school, in Dade County, Florida. No attempts will be made to determine if the results are generalizable to a different Hispanic population.

2. Only students enrolled in ESOL classes during the designated semester will participate in the study.

3. Data collected from students who are not immigrant Hispanic limited English proficient students will not be utilized in the data analysis i.e. Russian, Vietnamese, Chinese, Haitian, and Portuguese.

\section{Limitations}

The following two limitations apply to this study:

1. Attrition due to mobility, transfers and withdrawals, may alter the number of students from the beginning to the end of the semester. 
2. While all the students in the study were of Spanish speaking countries of origin the proportions varied from each country in the experimental and control groups (see Table 4, Chapter 3).

\section{Summary}

This chapter included demographic data and dropout issues including low selfesteem, poor attendance and counselor under utilization of the immigrant Hispanic language minority population. Prevention and intervention strategies presented in the literature were discussed. Escalating dropout rates of immigrant Hispanic LEP students and a lack of adequate intervention strategies in the literature led to the problem addressed in this study, its purpose and significance. A thorough review of the literature will be presented in Chapter II. 


\section{Review of the Literature}

This study examined the effect of group counseling on the self-esteem, attendance and counselor utilization of immigrant Hispanic limited-English proficient school students at a suburban high school in Dade County, Florida.

The purpose of this section is to summarize the literature and review selected studies that offer relevant information to this study. The review of the literature is divided into three sections. First, a summary of the dropout literature on language minority students, specifically limited English proficient (LEP) Hispanics, is presented. Included are the characteristics of potential dropouts and possible causes for dropping out. Section two reviews the literature pertaining to the role self-esteem/self-concept and acculturation for language minority students. Section three will provide an overview of the literature on counseling and counselor utilization of language minority students.

\section{Dropouts}

Schools are expected to prepare students to become productive members of society. In spite of compulsory attendance laws, the large numbers of students who dropout before completing high school are a growing concern for educators. Technological advances in the labor market decrease the number of low-skilled jobs, leaving high school dropouts further and further behind (Reyes \& Jason, 1993). Thus, 
there is a renewed national attention on the problem of high school dropouts. Programs, services, and intervention strategies continue to surface to alleviate the problem.

An analysis of the dropout literature reveals that the national rate has decreased over the last century. In the early 1900 s, only $4 \%$ of America's youth completed high school (Papagiannis, Bickel \& Fuller, 1983) increasing to $33 \%$ in $1930,50 \%$ in 1950 , and $76 \%$ in 1970 . Thus, by 1970 , approximately one out of every four students, or $25 \%$ did not graduate from high school. By 1980 that rate had dropped to $15.7 \%$ and by 1985 it was at an all time low of $15.2 \%$ (U.S. Bureau of the Census, 1991).

Since data on dropouts began to be gathered there have been conflicting definitions of the term "dropout." This has made it difficult to establish if an individual is or is not a dropout. Rumberger (1987) in one of the most extensive dropout studies, defines a dropout as someone not graduated from, or not enrolled in, a full-time state approved program. He goes on to say that although most states classify persons receiving a General Education Development (GED) examination or a high school equivalency diploma as a dropout, the Census Bureau does not consider persons enrolled in school or who received an equivalent certificate as a dropout. There are cooperative efforts under way, states Rumberger, between the U.S. Department of Education and Council of Chief State School Officers to decide on one definition of dropping out.

Chavez, Belkin, Hornback and Adams (1991) cite the following terms that are used synonymously with dropouts throughout the literature: "disaffiliated students (i.e., one no longer wishing to be associated with the school), capable dropout (i.e., family or 
cultural situations did not agree with school demands), stopouts (i.e., dropouts who return to school usually within the same academic year), and pushouts (i.e., individuals who feel sometimes quite accurately, that people in the school want them to leave)." (p. 5).

Minority dropouts.

Dropout rates vary among different ethnic, racial, and language minorities. Census (1985) data indicate the dropout rate for African American males and females declined from $23.8 \%$ to $19.7 \%$ and $24.7 \%$ to $14.5 \%$ respectively from 1968 to 1984 . Although the dropout rate for Hispanics show a decline during the same period, the average for both males and females hovers over $26 \%$ for each. Of all the major racial/ethnic groups, Hispanics have the highest dropout rates (Velez, 1989). For white, non-Hispanic males, and females the dropout rates were $15.8 \%$ and $14 \%$ respectively.

The National Center for Education Statistics gathered data on dropouts for three years, 1987-89 using two kinds of rates: event and status. Students leaving without completing school during a single year are reported as the event rate. For students in grades 10-12 from October, 1987 to October, 1989 , the average event rate was $4.5 \%$ per year or approximately 429,000 per year. The status rate is cumulative and it represents the individuals not enrolled in school and who have not finished school. Nationally, the status rate for $16-24$ year old persons was $12.6 \%$ in October, 1989 compared to $16.2 \%$ in 1968. The decline in both event and status rates is evident (Kaufman \& Frase, 1990). McMillan (1992) reports similar findings on the event and status dropout rates using 1992 data from the Current Population Survey of the Census and the National 
Education Longitudinal Study of 1988. The event rate was $4.5 \%$ in 1992 and the status rate dropped to $11 \%$. The study found that the higher the income the lower the dropout rate and that the difference between Whites and Blacks is narrowing. The Black status dropout rate has declined from $27.1 \%$ to $14.9 \%$ thus narrowing the difference between Blacks and Whites from 12.7 to 1.4 percentage points (Kaufman \& Frase, 1990). Persons from Hispanic American families and those living in southern and western areas were more likely to be status dropouts. They cite the high school completion rate in 1992 to be $86 \%$.

Conversely, Hispanics are not achieving comparable completion rates. There is an abundance of data in the literature which indicates the serious and widespread problems of high dropout rates, and low achievement of Hispanic students. Large enrollments of Hispanic school age children suffer from the problems in California, New York, Texas, Arizona, Florida and Illinois. In California $45 \%$ to $50 \%$ of the Hispanic high school population never graduate (Doyle, 1987), Chicago Public Schools report a consistent attrition rate of $50 \%$ over the past 10 years (Kyle, 1984) and New York dropout figures show $62 \%$ for Latinos according to the New York Dropout Task Force on the dropout problem (Marin, 1990).

Since 1972, when data first became available, Hispanic dropout rates have remained constant at the 30\%-33\% range. The Hispanic dropout rate in 1989 of $34.4 \%$ indicates that they drop out twice as much as Blacks or Whites whose dropout rates average 15\% (Kaufman \& Fraser, 1989). Overall, the attrition rate for Hispanic students 
in high school is $40 \%$ (Children's Defense Fund, 1991). A recent study by the U. S. General Accounting Office (GAO) (1994) using data from the 1990 Bureau of the Census found that "the dropout rate for Hispanics has been relatively constant for the past 20 years in contrast to the declining dropout rate for white and black non-Hispanics" (p. 3). The study cites that Hispanics, ages 16 through 24, have a 30\% dropout rate while nonHispanic blacks have an $18 \%$ rate and non-Hispanic whites have a $10 \%$ dropout rate (U.S. GAO, 1994)

Findings of a study in Texas of "at risk" students indicate that high school Hispanic and Black male students were more likely to dropout before graduation. A state legislative mandate in Texas forced school districts to identify elementary and secondary students at risk of dropping out. The Austin district reported students that met the following "at risk" factors: overage, poor grades, and failure on the Texas Educational Assessment of Minimum Skills (TEAMS). For grades 7-12 the findings for the 1990-91 school year were: (a) $44 \%$ of the total enrollment were "at risk," (b) students in grades 912 were more at risk than 7 th and 8th graders, (c) Hispanic and Black students were more at risk than other groups, and (d) $47 \%$ of males were at risk, compared to $39.6 \%$ of females (Frazer \& Nichols, 1991).

The dropout rate for Hispanics becomes a salient problem based on the demographic growth projections of this population for the future. Immigration, birth and mortality rates indicate that the Hispanic population will continue to grow at a faster rate than the U.S. population. Chapa and Valencia's (1993) descriptive analysis of population 
counts from the 1990 Census and the Census Bureau's Current Population Reports substantiate the increase of Hispanics in the United States. They found that between 1980 and 1990 the Hispanic, or Latino population, increased by $53 \%$ compared to a $9 \%$ increase in the total U.S. population in the same time period. Based on this rate of growth it is estimated the 15.8 million Hispanics living in the U.S. in 1982 will double by the year 2010 .

Many Hispanic students are also language minority students based on the definition of language minority according to Office of Bilingual Education and Minority Language Affairs (OBEMLA) (1992). They define language minority students as "those whose family or home language was other than English" (OBEMLA, 1992, p. 5). Among researchers, the language spoken at home is often used to categorize students beyond ethnicity and race. Gringas and Careaga's (1989) definition of language minority students concurs with OBEMLA's definition, i.e., one coming from a home where a language other than English is spoken.

Part of the language minority population is limited English proficient and another part is not (OBEMLA, 1992). All limited English proficient (LEP) students are language minorities but not all language minority students are LEP. Limited English proficiency, or LEP status, is measured by a language assessment instrument. When analyzing, interpreting, and forecasting the population growth and dropout rates of Hispanics, "the data should be seen as high estimates because not all people who speak a language other than English at home are limited English proficient" (Careaga, 1989, p. 2). 
Limited English Proficient Students' Demographics

Research on the size of the limited English proficient (LEP) population yields varied results based on the methods used to gather the data. Nationally, many factors influence the number of students reported to be LEP since the definition varies from state to state. At the state level, states receiving Title VII funds are required to report the numbers of LEP students receiving services (Henderson, 1994). Census data is limited in that portions of the population may be omitted and a subjective scale is used to determine English proficiency (NCBE, 1995).

The National Center for Education Statistics (NCES) compared data from State Education Agencies (SEA) receiving Title VII funds, of the overall LEP population for a period of eight years from 1985-86 to 1992-93. They found that the LEP population increased at an average $9.2 \%$ per year while the overall student population increased by approximately $1 \%$ annually. In a one year period, from 1991-92 to 1992-93 the LEP population increased at a rate of $12.6 \%$. During the eight-year period the LEP students' proportion to the total student population increased from $3.3 \%$ to $5.7 \%$. There are no indicators that the growth of this population will diminish in the future (Hopstock \& Bucaro, 1993). Chapa and Valencia's (1993) data indicate that between 1979 and 1988 the total number of school age children decreased by $2.9 \%$ but the total number of LEP students increased by $49 \%$. They attribute this growth to the rising number of immigrants in the late 1970 s and 1980 s. 
The most recent enrollment figures as reported by State Education Agencies (SEAs) indicate a 16\% increase from the 1992-93 school year to the 1993-94 school year.

Figure 1 shows a year-by-year comparison of LEP student enrollment as reported by SEAs.

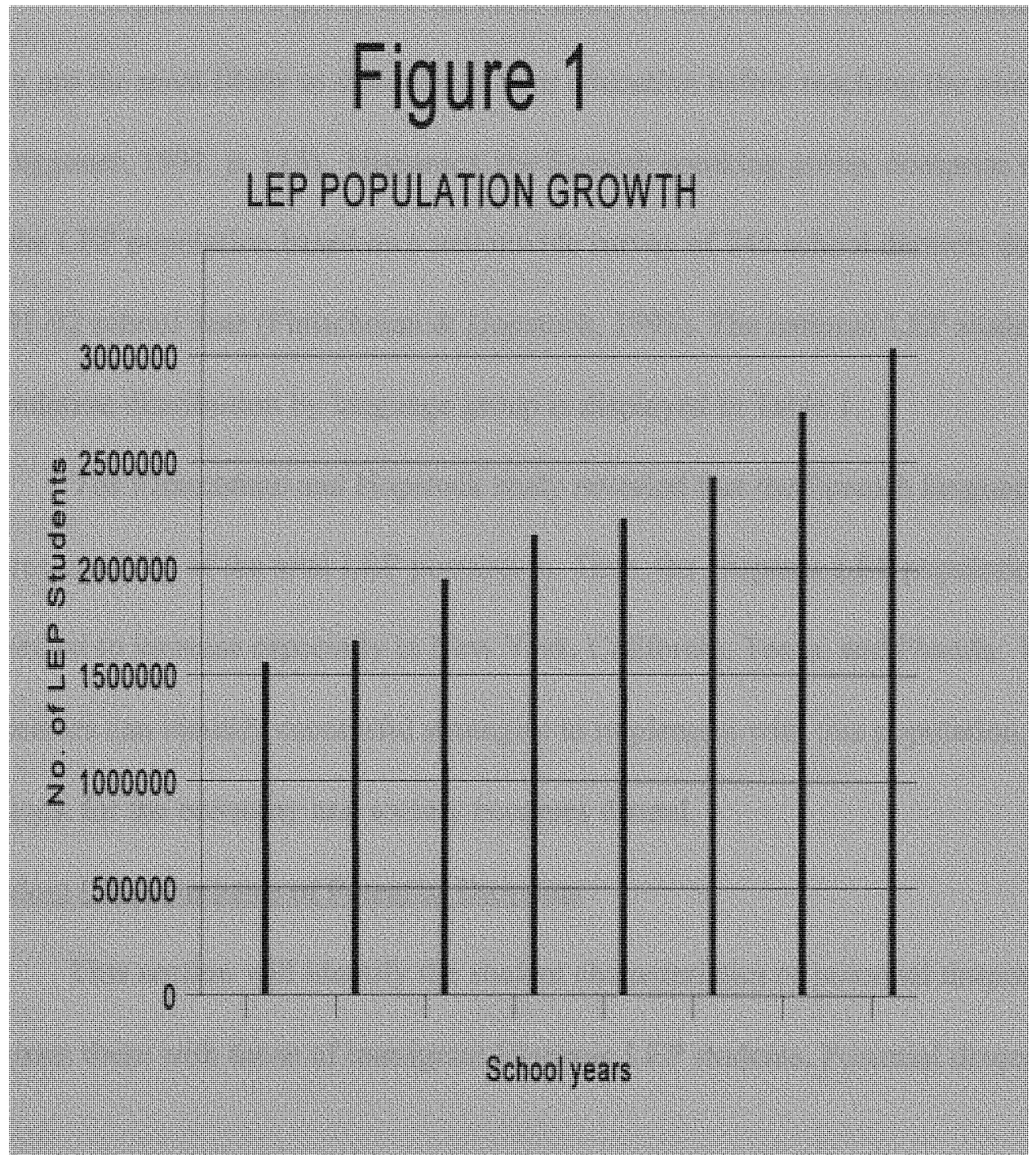


The average yearly increase in the number of LEP students for the period 1985 to 1994 was $9.6 \%$. The highest annual increase, $17.5 \%$, occurred between the $1987-88$ and 1988-89 school years. Dade County, Florida, is the fourth largest school district in the United States. During the 1993-94 school year, 54,735 or $13.0 \%$ of the total number of students were LEP students (NCBE, 1995).

"Hispanics as a group are the most likely of all youth to be undereducated, and they are the most likely to discontinue their education before reaching the ninth grade" (Waggoner, 1991, p. 115). Hispanics, the Spanish speaking group, comprise the majority of the LEP population based on a nationwide survey of 745 school districts during the 1991-92 school year (Fleischman \& Hopstock, 1993). The national LEP student population distribution by language group is displayed in Table 1 .

The Fleischman and Hopstock study revealed that the Spanish language group represents $73 \%$ of the total LEP population. Thus, the Hispanic LEP population can be expected to increase especially in New York, California, Texas, and Florida. Unless educators can identify successful strategies to implement with this population, the outlook for the economy and society becomes dismal.

\section{Student Characteristics of Potential Dropouts}

This section will identify the student characteristics of potential dropouts and contrast them with those of immigrant Hispanic LEP students. Potential dropouts are 
Table 1

LEP Student Population by Language Group

Language Group No of LEP Students $\quad$ \% of LEP

$\begin{array}{lrl}\text { Spanish } & 1,682,560 & 72.9 \% \\ \text { Vietnamese } & 90,922 & 3.9 \\ \text { Hmong } & 42,305 & 1.8 \\ \text { Cantonese } & 38,693 & 1.7 \\ \text { Cambodian } & 37,742 & 1.6 \\ \text { Korean } & 36,568 & 1.6 \\ \text { Laotian } & 29,838 & 1.3 \\ \text { Navajo } & 28,913 & 1.3 \\ \text { Tagalog } & 24,516 & 1.1 \\ \text { Russian } & 21,903 & 0.9 \\ \text { Creole } & 21,850 & 0.9 \\ \text { Arabic } & 30,318 & 0.9 \\ \text { Portuguese } & 15,298 & 0.7 \\ \text { Japanese } & 13,913 & 0.6 \\ \text { Armenian } & 11,916 & 0.5 \\ \text { Chinese } & 11,540 & 0.5 \\ \text { Mandarin } & 11,020 & 0.5 \\ \text { Farsi } & 8,563 & 0.4 \\ \text { Hindu } & 7,905 & 0.3 \\ \text { Polish } & 6,747 & 0.3\end{array}$

Source: Fleischman and Hopstock, 1993 
often referred to as "at risk" students. The term "at risk" became popular during the 1980s. Dougherty (1989) states that young people who are not engaged in a successful education are at risk of not getting a diploma, of not pursuing a higher education, of not finding successful employment and not becoming productive members of society. Educators and researchers have struggled to define who is at risk by identifying factors or criteria that may indicate a student's propensity to drop out. By identifying these characteristics educators can implement programs and policies to keep this population in school or bring back those who have dropped out to complete their high school education.

During the 1980s research efforts intensified to identify characteristics synonymous with dropouts despite the long term decline in dropouts. Rumberger (1987) cites four reasons for the growing concern of educators with the dropout problem: (a) the short-term trend has increased, (b) minority populations, who dropout at higher rates, are increasing in numbers, (c) legislation has been enacted to raise requirements for graduation, and (d) a higher level of skills will be required to enter the work force in the future.

States and local districts conducted studies to gather quantitative and qualitative data in order to devise profiles of at risk students. One problem with these studies is that they resulted in lists of reasons why students left school. These reasons evolved into checklists of characteristics used to identify potential dropouts (Dougherty, 1991)

Although there is no one reason why students drop out, much of the research initially focused on personal and family characteristics of these students. Factors 
associated with dropping out are grouped into several major categories that differ from study to study. Some researchers classify the factors as: demographic, family related, peer, school related, economic, and individual while others cluster them into broader categories such as personal, academic, and social (Rumberger, 1987; Wylie \& Hunter, 1994).

Demographic factors include socioeconomic status, gender, race, and ethnicity. Family related factors consist of educational level of parents, income level, and single parent families, while peer factors involve associations with friends who are dropouts. School factors which can be addressed through programs designed by educators include low academic achievement, truancy, poor attendance, grade retention, and disruptive behavior. Whether students have to or want to work, and how many hours per week they work are among the economic factors impacting potential dropouts. Low self-esteem, educational and occupational aspirations, marriage, and pregnancy are cited as individual factors (Rumberger, 1987). More recently, theories underscore factors such as: dysfunctional family structures, poverty, abuse, grouping students by ability (tracking), lack of parental involvement due to language and cultural barriers, schools being too large and impersonal, majority of teachers being white and middle class and know little about their students' cultures, and the curriculum does not reaffirm culturally different students (Fenelon, Khoxayo, Kwiat \& Rodriguez, 1993).

The three broader categories as stated by Wylie and Hunter (1994) are (a) personal, (b) academic, and (c) social. Personal factors include being older than peers 
due to retention, being from a racial/ethnic minority group, low self-esteem and alienation. Academically, dropouts experience academic failure, and exhibit poor attendance, negative behavior, truancy, and boredom in school. Social indicators include socioeconomic status, level of parents' education, little or no participation in school activities, and peer associations (Wylie \& Hunter, 1994)

Multiple researchers, cited in Rong and Preissle-Goetz (1990), have summarized the factors contributing to the problem of high school dropouts among American youth to be: race or ethnicity, gender, marriage at a young age, parent's education and family incomes, and years of retention. Gringas and Careaga (1989) combine the dropout indicators of The Florida Department of Education (1986) and the typology of Natriello, et al (1984) into an inclusive list of risk factors displayed in Table 2.

\section{Empirical Studies on Dropout Characteristics}

During the 1980s, multiple studies were done to identify who were the dropouts and why they left school. The High School and Beyond study (Ekstrom, 1986) provides baseline data from a national sample as to the variables common to dropouts. Data were gathered in this study using self report methods where students identified the reasons why they left school. According to Perez Miller, (1989) these reasons vary but they are interrelated and fall into three major categories: "those related to school experiences, those related to family condition, and those related to economic factors" (p. 122).

Wylie and Hunter conducted their study in South Georgia High Schools from 1990 to 1993 to identify students who dropped out and their reasons for doing so. They 
Table 2

Potential Dropout Indicators and Risk Factors

Dropout Indicators

Risk Factors

Lack of positive

Two years or more older than

relationships in school

peers

Limited extracurricular

activities

Unable to identify with peers

Friends all outside the school

Socializing with drug users,

delinquents or persons who

attempt suicide

Perception that school

Absenteeism/truancy/tardiness

program is irrelevant to

Lack of definitive goals

their future

Alienation from school

Fail to see relevance of

education to life experience

Discrepancy between ability

and performance 
Insufficient opportunities

for success in school

Family factors outside

of school 
Parents are migrant workers

Language other than English at

home

Personality Factors

Inability to tolerate

structured activities

Disruptive classroom behavior

Poor social adjustment

Difficulty relating to

authority figures

Health problems

Experience some form of trauma

Poor self-concept

Excessive hours spent on a job

Lure of more gratification

for outside job, wages, and

experiences

Source: Careaga, R.C. (1988, Fall). Keeping limited English proficient students in school: Strategies for dropout prevention. National Clearinghouse for Bilingual

Education, (7), 1-20. 
expressed concern that changing statistics on dropouts may not be accurate. They claim that figures "may or may not include the sophisticated tracking necessary for accuracy in determining how many students move away and enter during a particular year, and how many drop out and later return" (Wylie \& Hunter, 1994, p. 75). After interviewing 18 educators and 36 students in six dropout prevention programs, they developed a composite profile of "Danny Dropout" based on personal, social, and academic characteristics. The major characteristics identified in this study were "pressure" and "boredom." Students identified pressures related to family, peers, jobs, and sex. Academically the boredom stemmed from an irrelevant curriculum, teachers ignoring troubled students and a poor education for students in low-ability tracks (Wylie \& Hunter, 1994).

Socioeconomic status has been linked to dropouts in numerous studies. The literature indicates that economic factors such as the need to generate income, and social class are correlated with dropout rates. In a study of 440,000 ninth graders, Combs and Cooley (1968) found that $50 \%$ of both boys and girls who dropped out were from the lowest quartile of the socioeconomic scale. Peng (1985) found that $17 \%$ dropped out from the lowest quintile of the high school sophomore population while only $5 \%$ of the top quintile did not graduate.

Sociopsychological factors have been related to dropout behavior. Among them are (a) the student's expectation of his/her educational achievement, (b) education of the parents, (c) family structure and size, (d) parental involvement in the child's education, (e) 
domestic problems, and (f) parental emphasis and educational aspirations for their child. Measurable and visible influences on dropouts from the school's perspective include poor attendance, truancy, negative behavior, boredom, and academic failure. Other affective factors are low self-esteem and alienation (Reyes, 1989).

\section{School factors - attendance.}

The Dropout Interview Study in Cincinnati (1989) attempted to identify and compare the characteristics of its own dropouts to those identified in national studies. Investigators used an interview schedule developed by school personnel, representatives of social service agencies and community representatives. They interviewed one group of 308 students who had two characteristics of dropouts but had graduated from high school. The second group comprised 709 dropouts. Results indicated that course grades were a better predictor of risk than standardized test scores and that the dropouts had an average of 59 days absent a year compared to 18 days for the in-school group. Seventy-eight percent of the dropouts had been retained in grades 9-12 and they had a feeling of persecution by school officials. Among the significant social/family findings were: pregnancy, drugs, child care, alcohol, and educational level of parents. The most significant finding was that $40 \%$ of the dropouts worked an average of 31 hours per week compared to 20 hours for the group who graduated (Gastright, 1989).

Results of the Dropout Interview Study suggest that current performance in school is the strongest indicator of a student being "at risk." Performance is measured in the study by absenteeism and failing grades. Parent education, student's arrest record, family 
background, student's employment as well as drugs, pregnancy, and child care were among the social characteristics of the dropouts in this study.

Matute-Bianchi (1986) conducted an ethnographic study in central California in which she looked at how ethnicity, minority status and perceptions of adult opportunities affected school involvement and performance. The study compared students of Japanese background with students of Mexican background. Matute-Bianchi categorized students of Mexican descent into five categories: (a) recent Mexican immigrants, (b) Mexican oriented, (c) Mexican-American, (d) Chicano, and (e) Cholo. Differences among the groups included their attitude towards school, their participation in school activities, and overall performance. The recent immigrants, Chicano and Cholo groups were the least successful. Recent immigrants cited lack of proficiency in their own language as a reason for failure. These are LEP students in English for Speakers of Other Languages (ESOL) classes. The Chicano and Cholo groups rejected academically oriented Mexican peers, were not involved in school activities, had high absenteeism, disruptive behavior, and were in remedial courses. The most successful students were the Mexican oriented and Mexican American because they were involved in school organizations, but not those organizations that were solely "Mexican." The Japanese students in this study, unlike the Mexicans, had role models, experienced positive attitudes from teachers who perceived them to be smart in math and science, and did not have a need to emphasize their ethnic identity through clubs and organizations. 
Mendoza, (as cited in Perez Miller, 1989), states that assimilation into the dominant Anglo culture has been perceived by parents and educators as synonymous with educational, economic, and social success. The findings of Matute-Bianchi (1986) concur with Mendoza's theory as the Chicano and Cholo group perceive assimilation as the negation of the Mexicanness. Thus, their inability to assimilate resulted in their failure in school.

Matute-Bianchi and Mendoza's findings conflict with Rumbaut's (1995) study with over 5,000 children of immigrants. The participants, eighth and ninth graders, were either foreign born or U.S. born with at least one foreign born parent. The study revealed a negative relation between length of resident in the U.S. and grade point average (GPA). That is, the longer the student resided in the U.S., or having been born in the U.S., the lower the student's GPA. Proficiency in English, having a peer group of co-ethnic friends, and the time spent on homework were found to be positively related to GPA and higher educational aspirations (Rumbaut, 1995).

Alienation, disengagement, poor self-image, and low or negative self-esteem negatively impact a student's personal educational aspirations. The plight of Blacks and especially Hispanics is intensified if they believe that they will never have equal opportunities regardless of their education (Fine \& Rosenberg, 1983). Negative attitudes, lower expectations and prejudice from teachers may affect student self-esteem (Reyes \& Jason, 1993). 
In an effort to understand successful Hispanic students, Reyes and Jason, (1993) conducted a study in an inner city high school in Chicago. The student body was predominantly minority and economically depressed. They identified two groups of 24 Hispanic, 10th grade students similar in socioeconomic status and family structure. One group was considered to be at high risk for dropping out because they had more than 15 days absent per semester and were failing a minimum of three classes. The low risk group had no failures and less than seven days absent. Participants completed a structured interview and a self-report self-concept measure. Family factors had little impact on the results of this study. Low risk students were more satisfied with their school, experienced less "put down" from teachers, and conformed to school rules. The most significant factor differentiating the two groups was the invitation for gang membership. The researchers concluded that "since low risk students received more positive attention and feedback from teachers....this in turn facilitated their interest in school and their optimism about their academic future" (Reyes \& Jason, 1993, p. 68). A recommendation is made that schools incorporate self-esteem enhancing strategies into the teaching, curriculum and administration.

Immigrant Hispanic dropout characteristics.

Factors unique to linguistic or language minority students are also found in the dropout literature. Fluency in English, language of the family, age at immigration (Gibson, 1987; Jones, 1985; Rumberger, 1983; Steinberg, 1984) and prejudices against immigrant minorities (Bowler, Rauch \& Arzer, 1986; Hinojosa \& Miller, 1984; Suarez- 
Orozco, 1987) are cited in the Rong and Preissle-Goetz (1990) study done on high school dropouts among foreign born Whites, Hispanics and Asians. Their study utilizes data from the Census Bureau to offer a national perspective as they focus on a sample of 519 foreign-born youth aged 16-21.

In the above named study Hispanic immigrants exhibited an alarming $49 \%$ dropout rate compared to $15 \%$ for foreign-born Whites and $11 \%$ for foreign-born Asians. They found that foreign born Hispanics (a) are more likely to be married than Whites and Asians, (b) are four times more likely to report speaking poor English than Asians, (c) came to the U.S. at an older age than Asians, and (d) are less likely to reach 12th grade than Whites and Asians. Rong and Preissle-Goetz concluded that "the most uniform predictor for the total and for the three ethnic groups is the ability to speak English" (p.22). Furthermore, they speculate "that the socioeconomic influence may not only increase dropout rates independently, it may also interact with English ability, family language background and age at immigration; together they aggravate the drop-out problem" (p. 24). Their findings concur with Steinberg et al. (1984) that about 50\% of Hispanic foreign-born aged 16-21 subjects were dropouts as a result of a non-English or limited English background as well as being from low income families.

Poor academic achievement, or failing grades, and functioning or reading at below grade level, are correlated to dropping out of the general population as well as for racial/ethnic minorities throughout the literature. Perez-Miller (1989) states that limitedEnglish proficient (LEP) students confront difficulties and limitations as they struggle to 
succeed academically in classes where instruction is in English. She reaffirms that native language proficiency has a strong correlation to how LEP students perform academically in the content areas. Studies indicate that mathematical competence is a better indicator of academic achievement for LEP students than ability to read in English.

In a summary of factors affecting Hispanic students in the schools, Perez-Miller (1989) concludes that: (a) Hispanics drop out at rates higher than other minority students regardless of socioeconomic status, (b) first and second generations do better in school than subsequent generations, (c) low and high acculturation are more positively related to school performance, (d) math and native language ability are better predictors of academic achievement, (e) being overage as a result of being retained has negative effects on students' achievement, and (f) more accurate and appropriate assessment instruments and procedures to evaluate Hispanic, specifically LEP students are needed.

\section{Debilitating Factors for Language Minority Students}

Variables linked to the failure in school of language minority students include: fluency in English, alienation, loss of a sense of identity, low self-esteem/self-concept (often referred to as self-confidence and security), attitude towards the majority population, prejudices against immigrants, teachers' attitudes, being judged by lower standards because of teachers' expectations, high levels of anxiety, and a perceived sense of worthlessness or helplessness resulting in a lack of motivation (Gringas \& Careaga, 1989; Rong, 1990; Sanchez, 1981). Coping with such conflicts leads to isolation, passivity, withdrawal, truancy, aggressive hostility and drug and alcohol abuse (Sanchez, 
1981). Studies by Grey (1991), Minicucci (992), Sinclair (1992), and Spener (1988) as quoted in Watt and Roessingh (1994) found that language minority students suffer from frustration and marginalization culminating in dropping out of school.

Canadian studies that examine the educational success of immigrant students reveal alarming results. Randwanski's (1987) study noted an increase in LEP students' dropout rates reaching 53\%. A recent study by Alberta's Department of Education (1992) reported an even higher $61 \%$ dropout rate for LEP students enrolled in English for Speakers of Other Languages.

Fluency, competency or proficiency in English emerged as the most powerful predictor of success in a recent study of LEP high school students. Watt and Roessingh (1994) conducted a study with LEP students enrolled in English for Speakers of Other Languages (ESOL) in a large urban high school in Alberta, Canada between 1988 and 1993. They examined various factors thought to be predictive of academic success: gender, age on arrival, first language ability at entry, country of origin, home language, number of languages spoken, educational gaps, immigration status, and English language proficiency at entry. Results indicated that: (a) students entering at the intermediate or advanced levels of English proficiency had an $86 \%$ graduation rate, (b) students entering at the beginner, or no English level, required four years of ESOL, intermediates required two years and advanced required only one year, and (c) $90 \%$ of those ESOL students who graduated received a General Diploma compared to $42 \%$ of all the graduates who 
received a General Diploma and 55\% received an Advanced Diploma (Watt and Roessingh, 1994).

In a study done with Mexican-American, Puerto Rican, Cuban, other Hispanic, Asian, and American Indian children, competency in English showed positive relationship with academic grades and with mathematics achievement. Baratz-Snowden's et al., (1988) findings in this study supported Gringas and Careaga's (1989) statement that "high competence in English leads to good academic performance which, in turn, leads to lower dropout rates" (p.3).

A summary of the research data from the literature on immigrant, Hispanic students as well as that of immigrant LEP Hispanics, indicate that English language proficiency is correlated to the success in school of this population (Rong, 1990; Steingberg, 1987; Perez Miller, 1989; Gringas \& Careaga, 1989; Baratz-Snowden et al., 1988). Success in school is measured by good academic performance. The limited number of studies that examine the dropout rates of this population reveal alarming rates ranging from $49 \%$ (Rong, 1990) to 74\% (Watt \& Roessingh, 1994). Besides English language proficiency, a high acculturation level has been associated with success in school whereas excessive absences and low self-esteem have been identified as debilitating factors leading to escalating dropout rates. A lack of empirical studies to investigate strategies that could affect the attendance, counselor use and self-esteem of immigrant Hispanic LEP students, coupled with the researcher's experience as a secondary school counselor, prompted the interest and need for this study. 
Immigrant Status

Foreign born, Spanish language background Hispanics are the most likely group to be: undereducated, failing to reach the ninth grade, from families with incomes below the poverty level, from low levels of schooling (Waggoner, 1991). Many LEP students enrolled in ESOL (English for Speakers of Other Languages) classes at the secondary level are recent immigrants to the United States. They come to the United States legally or illegally, for political, social, economic, and educational reasons. As immigrant adolescents they have hopes, dreams and aspirations that may be defeated by fears, prejudice and failure in a foreign culture.

Being an immigrant is a major life upheaval. Arredondo (1986) contends that immigration creates a behavioral and psychodynamic sense of disequilibrium, i.e. an identity crisis. The immigrant's self confidence and competence are undermined as support systems are lost. Based on a longitudinal study with immigrant adults, an ongoing clinical practice, and the mentoring processes with immigrant students, Arredondo proposes a parallel to Erikson's Life Cycle tasks for immigrants, summarized in Table 3.

In the first life-cycle task Arredondo depicts the uncertainty, fears, and suspicions immigrants face when entering a foreign system and how these feelings impede positive experiences which in turn lead to trust. The embarrassment in the second life task comes from not speaking the language well and being made fun of. Personal worth, esteem, erodes as one feels "different" from the majority. Having survivor's guilt in the third life task comes from the loss of leaving family and friends behind in their homeland. 
Table 3

Erikson's Life-Cycle Tasks and Virtues/Arredondo' Issues for Immigrants

ERIKSON'S LIFE CYCLE VIRTUES

TASKS

1. Trust vs. Mistrust

2. Autonomy vs. Shame and Doubt

3. Initiative vs.

Guilt

4. Industry vs.

Inferiority

5. Identity vs. Identity

Confusion

6. Intimacy vs.

Isolation

7. Generativity vs.

Stagnation

8. Integrity vs. Despair
Hope

Will

Purpose

Competence

Fidelity

Love

Care

Wisdom
LIFE CYCLE ISSUES

FOR IMMIGRANTS

Confusion About Trust

Embarrassment/ Humiliation

Survivor's Guilt

Inferiority about Competence

Confusion about Who One

Really Is

Feeling Stuck and

Overwhelmed

Feeling Lost and

Disconnected

Sense of Hopelessness 
In the fourth life task, subservience is developed when immigrants are forced to find jobs inferior to the one they had at home because they are illegal and/or they do not speak the language. Once again, their self-worth is questioned. The identity confusion, in the fifth life task, is evident in the estrangement that immigrants experience as they leave their social and group identity in their homeland. As immigrants acculturate and acquire a "sense of belonging" an identity is reestablished. The sixth life-cycle task, involves being productive. Encountering difficulties and rejections leads the immigrants to feel immobilized as they struggle to cope. In the seventh life cycle task the immigrant experiences loss which Arredondo defines in terms of "language, lifestyle and climate" (p. 83). Connectedness to the new culture may occur sooner if one has family in the new country. Lastly, the immigrant seeks to regain a sense of integrity after wondering if the decision to migrate the right thing to do. Arredondo's recapitulation of Erikson's lifecycle tasks for the immigrant demonstrates the results of immigration to be a loss of esteem and identity.

In the 1970s the emphasis of research done to address the needs of students changed from methodology of instruction to an understanding and awareness of personal and social variables. Maslow's (1970) theory of motivation is based on a hierarchy of needs. According to his theory one cannot progress to satisfy the higher order needs, including esteem, if the basic safety and emotional needs are unmet. For many new immigrant students, especially those that come into this country illegally, the possibility 
of success at academics is remote since their home environment is often unstable and insecure.

\section{Self-Esteem and Ethnic Identity}

In the fall of 1979, the San Mateo Community College District in California conducted a survey to assess the needs of the Latino or Hispanic population. Entitled the Chimexta Project, it surveyed seven groups of Latinos including high school students, college students, students who had graduated, adults who were members of community organizations, faculty and staff, and community service workers who served Latino clients. The results indicated that for high school students the most significant problems were ethnic identity and cultural conflicts. The intrinsic conflict was the partial rejection of their own Hispanic culture and the incomplete assimilation into the American traditions and English language.

Besides culture conflict and ethnic identity the most significant problems for Latino youth in the Chimexta Project were racism, lack of sufficient and effective education, lack of successful bicultural role models, lack of bilingual programs, and poor attitudes towards school. Over $50 \%$ of the respondents to the survey identified three strategies to improve the education of Hispanics: (a) providing bilingual classes, (b) helping students achieve confidence and a sense of self-worth, and (c) adapting teaching methods to the needs of the students (de la Rocha-Petris, 1980).

Ethnic identity, according to Phinney (1991), "is a multidimensional construct, involving ethnic feelings, attitudes, knowledge and behaviors" (p. 193). Beyond the 
definition, Phinney (1991) identifies the following key elements of ethnic identity: self identification as a group member, attitudes and evaluations relative to one's group, attitudes about oneself as a group member, extent of ethnic knowledge and commitment and ethnic behaviors and practices. One who has high, strong, secure ethnic identity has positive regard for his/her cultural group, engages in ethnic practices, prefers or is comfortable with members of the same culture. The other end of the continuum, little ethnic knowledge, interest, involvement, represents low or weak ethnic identity.

Evidence from studies indicate that these components of ethnic identity vary independently of each other across ethnic groups, across age groups within the same ethnic group and across generations. As such, it is necessary to examine how each component or element of ethnic identity affects self-esteem. Bernal, Saenz and Knight (1991) contend that ethnic identity is part of the self-concept. They propose that it is a psychological construct, a set of self-ideas about one's own ethnic group, that addresses the question, "Who am I?" Ethnic minorities must identify as group members and develop opinions and feelings about their group as well as ethnic values. Cross' (1978) model for Black identity formation, and Atkinson, Morten and Sue's (1983) Minority Identity Development Model for minorities claim that a healthy, complete identity is achieved when there is acceptance of one's own group and a positive attitude towards that group. Both models claim that over a period of time low ethnic identity evolves into high or achieved ethnic identity. 
Members of groups that are subject to prejudice, discrimination and negative stereotypes may have lower self-esteem (Tajfel, 1981). Evidence indicates that this is not necessarily true (Crocker \& Major, 1989). Research that differentiates between stereotypes about one's own group, and of others about one's own group shows that individuals tend to have positive feelings and perspectives of their own group (Triandis et al., 1982). Since individuals perceive that opinions of others may refer to their group but not to them individually, their self-esteem remains intact (Crocker \& Major, 1989).

In a study with Hispanic and Anglo eighth and ninth graders, Grossman, Wirt and Davids (1985) found that a positive evaluation of one's group, which they named "ethnic esteem," was positively correlated to self-esteem. Conversely, Houston (1984) found the attitudes of Black college students towards Blacks and whites had no correlation to selfesteem.

Studies done to investigate the acceptance or rejection of one's ethnic group membership to self-esteem reveals conflicting results. Two studies done in the late seventies and early eighties (Paul \& Fischer, 1980; Tzuriel \& Klein, 1977) found a positive relationship between ethnic identity and self-esteem. However, two other studies (Parham \& Helms, 1985; White \& Burke, 1987) found no relationship between ethnic identity and self-esteem.

Phinney and Alipuria (1990) conducted a study to examine various aspects of ethnic identity in relation to self-esteem with Black, Mexican Americans, Asian Americans and Whites. Results indicated that Black males and Mexican American 
females exhibited a positive relationship between interest in and knowledge about one's ethnic group and self-esteem. Asian Americans and Whites showed no relationship. Phinney (1991) attests that "no conclusion can be drawn about the relationship of cultural knowledge and self-esteem" (p. 201).

Commitment to one's ethnic group, the final component of ethnic identity, becomes relevant in adolescence when one has to integrate knowledge, attitudes and feelings acquired during childhood to societal and peer pressures. Similarly to the other components, studies reveal conflicting evidence. Phinney (1991) states that "the relationship (between ethnic commitment and self-esteem) is not likely to hold with those for whom ethnicity is not salient, as is generally the case for White students (p. 202). Given the inconclusive results of the relationship between self-esteem and ethnic identity, Phinney (1991) concludes that "the way individuals relate to the mainstream culture" may be a factor that impacts both of these constructs.

\section{Self-Esteem and Acculturation}

According to Phinney (1991) acculturation is how well an individual integrates into the mainstream culture. For ethnic and language minorities acculturation is the opposite of alienation (Phinney, 1991). The process of acculturation according to Berry et al., $(1987 ; 1989)$ can be defined in four stages depending on the individual's identification with their own ethnic group and with the majority culture. Marginalization indicates identification with neither group, separation with only the ethnic group, 
assimilation with only the majority culture, and integration with both the ethnic and the majority culture.

In a study of high school and college students, Phinney, Williamson, \& Chavira (1990) assessed the relationship between self-esteem and the four stages of acculturation. Significant positive correlations exist between self-esteem and the integrated individual, negative correlations were found with assimilated individuals and self-esteem and no correlation for separated individuals.

Willig, Harnisch, Hill and Maehr (1983) conducted a study with Anglo, Black and Hispanic students to determine who succeeded and who failed in school and why. Participants were divided into three groups based on their level of acculturation: low, moderate and high. They investigated achievement attributions, test anxiety, defensiveness, school performance and background characteristics. Moderately acculturated children, those not identifying with either culture strongly, exhibited the highest risk factors of higher defensiveness, higher test anxiety, and debilitating motivational variables including low self-concept of academic ability.

It is evident from the literature that Hispanics have a higher dropout rate than all other racial/ethnic minorities (Velez, 1989; Chavez, Belkin, Hornback \& Adams, 1991; GAO, 1994). The majority of the studies attempt to define what is "wrong" with students who are dropouts rather than identifying what are the characteristics of successful students. Delgado-Gaitan (1988) conducted a study to identify what enabled some Mexican-American students to stay in school while others left. She found that the 
successful students conformed to school rules and they received more social, emotional and familial support from their families than did those who dropped out. Other studies indicated that better educated parents influence children's motivation (Fernandez \& Paulsen, 1989) and spend more time with their children in educational activities (Beck \& Muia, 1980).

The relationship between acculturation and ethnic identity parallels that of acculturation and self-esteem. Ethnic identity evolves and changes as individuals acculturate to a new society. Using Berry's model of acculturation (Berry, 1980) Dona (1991) examined changes in ethnic self-identification and cultural behaviors of Central American refugees living in Canada. Participants responded to two attitude scales to identify with which nationality they identified themselves, and the degree of contact they had with the Latin and Canadian cultures. Findings indicate that participants in the integration mode had a more diversified identification with both cultures, whereas those in the assimilation mode identified with the Canadian culture, and those in the separation mode identified with their country of origin. As for contact with the Latin culture, both the integrated and separated individuals exhibited contact but those that were assimilated did not.

Cultural disparity or preexisting differences between minority and Anglo cultures cause conflict for students in school. Neither teachers nor students deliberately seek conflict due to cultural differences, yet they disrupt the teaching and learning process. Bernal, Saenz and Knight (1991) stress the importance of these disruptions by stating that 
they "lead to students' rejection of the cultural values and academic demands of the schools and consequently, to academic failure in ethnic minority children" (p. 139). Rumberger (1983) found that adolescents immigrating into the U.S. had more academic problems that those migrating earlier in life. Steinberg (1984) provided evidence for the cultural disparity theory through findings that language minorities had lower academic achievement and higher dropout rates than English language background students.

Research to understand why Hispanics do not perform as well as Anglo students has concentrated on cognitive and motivational variables that affect academic achievement. Studies of affective variables have hypothesized that self-concept and selfesteem affect motivation and expectations which in turn affect academic achievement (Chapman et al., 1981; Johnson, 1981). The literature on self-esteem in Hispanics reveals conflicting results. Some have found negative self-concepts in Hispanics, others no differences between Hispanics and Anglos (Larned \& Muller, 1979; Omizo et al., 1981), and yet others a significant correlation between self-esteem and reading in Hispanics (Powers \& Sanchez, 1982).

In a study to explore the discrepancy in academic achievement between Hispanics and Anglo students, Strassburger et al. (1990) explored the dimensions of academic selfesteem, locus of control and socioeconomic level and their effect on academic achievement. Their sample consisted of 371 junior high school student of which 304 were Anglo and 67 were Hispanic. Results indicated that Hispanics had a lower mean grade point average (GPA) than Anglos. There were no significant differences for self- 
esteem or locus of control between the two groups. Locus of control was positively correlated to achievement for Anglos but not for Hispanics. Self-esteem was found to have a significant effect on achievement for both groups. While Hispanics had a lower mean income than Anglos, socioeconomic status contributed very little to the differences in achievement. Based on the findings that self-esteem accounted for the largest amount of variance in the student's GPA, regardless of ethnicity, the researchers concluded that remediation in the area of self-esteem can be a part of programs designed to improve grades for all students.

Interaction between the dominant culture and minority group members can send a message to the latter that they are second class or inferior to the majority. Bernal et. al., (1991) state that if this interaction process is examined from a social identity approach, it is important to consider that our self-worth is an integral part of our social identity. Furthermore, they say, "individuals strive for a positive self-concept, and derive meaning from the valence associated with their group membership" (p. 147). As such, they conclude that conflict and low self-esteem are likely to develop if the minority group members perceive that they are devalued by the dominant majority.

\section{$\underline{\text { Self-Concept/Self Esteem }}$}

Throughout the literature of dropouts, specifically ethnic and language minority dropouts, self-esteem/self-concept surfaces as a factor of success or failure. In an effort to understand the academic deficiencies and below average performance of minority students, researchers have examined the relationship of self-esteem/self-concept on 
academic achievement (Reasoner, 1992). Many suggest that low self-esteem may be related to poor academic performance. The question often addressed is whether academic achievement causes high self-esteem or low self esteem, and is responsible for academic failure.

Definitions of self-concept and self-esteem vary in breadth and scope. Although interest in these constructs originated in the 1960 s with the humanistic movement, philosophers, psychologists, and counseling researchers had their own definitions a few decades earlier. According to Branden (1990), Freud referred to low "self-regard" in terms of a child's fantasy of a sexual relationship with either parent and gave us an understanding of internal mental processes. Adler related how one starts out with feelings of inferiority because we are not perfect from birth, and Fromm defined self concept as life being aware of itself. Self-concept was intertwined with the counseling profession in the mid-1900s as Lecky contributed that self-consistency was a motivator of human behavior, Raimy used measures of self-concept in counseling interviews, and Rogers introduced a theory of counseling that revolved around the importance of the self.

Purkey (1988) defines self-concept as "the totality of a complex, organized and dynamic system of learned beliefs, attitudes, and opinions that each person hold to be true about his or her personal existence" (p. 475). Three major qualities of self-concept are: (a) it is learned, (b) it is organized, and (c) it is dynamic. That self-concept is learned implies that one is not born with it and that it grows, changes, evolves, and is reshaped with life's experiences and interactions with significant others. That self-concept is 
organized implies that it is stable, consistent, and it resists change. That self-concept is dynamic implies that it is vital and vibrant. One learns new ideas and discards old ones always seeking emotional satisfaction and insuring that self-esteem is preserved (Purkey, 1988).

Byrne's (1974) definition of self-concept is that "self-concept may be defined simply as the total collection of attitudes, judgements and values which an individual holds with respect to his behavior, his ability, his body, his worth as a person, in short, how he perceives and evaluates himself" (p. 271). In one of his later works, Byme, (1984) concluded that self-concept was a multidimensional construct with one general factor and several facets, one of which is academic self-concept. Coopersmith (1967) offers this definition of self-concept: "... the totality of perceptions a person has about himself which are most vital to the individual himself and that seem to the individual to be 'me' at all times and places."

Hamachek (1987) differentiates between the public and private selves in each person. The "public" self is that part of us that we allow others to see. The self-concept, the more private part of our self, involves how we see ourselves. Cognitively we develop ideas and attitudes about ourselves as a result of our life experiences. Hamacheck refers to self-concept as "our own private mental image of ourselves, a collection of beliefs about the kind of person we are" (p. 10). There are four components to self-concept and they are unique yet interrelated. These four aspects include: a physical self-concept, a 
social self-concept, an emotional self-concept, and an intellectual self-concept. If the self-concept is low in any one of these areas then our self-esteem is also low.

Based on Hamachek's definition, the self-concept is the broader and cognitive part of our self perceptions and self-esteem is the affective or feeling part of our self perceptions (Hamachek, 1987). It describes how we evaluate, feel about, and describe ourselves. Coopersmith's (1967) definition of self-esteem also involves an evaluative component of the self. It entails one's approval or disapproval and to what extent one feels capable, significant, successful and worthy.

Branden (1990) offers a broader and more encompassing explanation of the construct of self-esteem. He defines it in terms of the sum of self-efficacy and selfrespect, the pillars of self-esteem. Self-efficacy means being able to think, judge, choose, know and decide i.e., being in control. Self-trust and self-reliance are inherent to selfefficacy. Self-respect means knowing our value and making value judgments, knowing our right to live and be happy and asserting our thoughts, wants and needs. Another vital component of self-esteem, according to Branden (1990) is self-confidence. "Confidence in our ability to think, confidence in our ability to cope with the challenges of life and confidence in our right to be happy, the feeling of being worthy, deserving, entitled to assert our needs and wants and to enjoy the fruits of our efforts."

Battle (1990) provides a more descriptive definition when he defined self-esteem as "the perception the individual possesses of his/her own worth. An individual's perception of self develops gradually and becomes more differentiated as he/she matures 
and interacts with significant others. Perception of self-worth, once established, tends to be fairly stable and resistant to change."

Although there is no consensus on what self-esteem means, the term is the focus of numerous research studies, books and magazine articles. Its advocates claim that selfesteem is a basic human need (Branden, 1990) indispensable to "normal and healthy development" (p. 16). Opponents object to the self-report measures used, (Baumeister et al., 1989; Kohn, 1994) claiming they are neither valid nor comparable.

Controversy on self-esteem has led to the formation of councils around the country. The California Task Force to Promote Self-Esteem and Personal and Social Responsibility, a state funded task force, was established in 1987 to investigate hard data on the topic. Their report, issued in 1990, identifies self-esteem as the single factor underlying social maladies and calls it a "social vaccine" against crime, violence, abuse, drug usage, teen pregnancy, and educational failure (Kohn, 1994). However, Kohn concluded after reviewing nine studies since 1980 that the data "offer more reason to doubt than to affirm the relevance of self-esteem" (p. 274). Thus, even though the correlation between high self-esteem and prosocial behavior was positive in the research reviewed, the results were dependent upon other variables such as gender (Kohn, 1994). Research data did not indicate a causal relationship between self-concept and achievement in children (Caslyn, 1974; Maruyama et. al., 1981; Rosenberg, 1989). In a large study done with high school students, Pottebaum et al. (1986) used a cross-lagged panel correlation to determine if self-concept and academic achievement were causally 
correlated. Their results suggest that there is no significant causal relation between the two, but that one or more other variables are predominant over self-concept and academic achievement.

Self-esteem has been referred to as "indispensable for a healthy, normal life," "a basic human need," and "a social vaccine." According to Walz (1991), it means we have

"a positive attitude, we evaluate ourselves highly, we are convinced of our abilities, and we see ourselves as competent and powerful--in control of our own lives and able to do what we want" (p. 483). Having high self-esteem, based on Walz's definition, empowers individuals to cope with developmental changes, to believe they can achieve their needs and wants, and to believe they deserve happiness (Walz, 1991). When individuals believe in themselves they can accomplish almost anything. This translates into motivation, confidence and effectiveness as well as an immunity to downfalls, rejections, and failures in life.

\section{Group Counseling and Counselor Utilization}

A California study by Miniucci and Olsen $(1991,1992)$ concluded that secondary LEP students are not adequately served because of: (a) the diversity and complexity of their needs; (b) a lack of support services to meet those needs; (c) a shortage of trained teachers; (d) inadequate assessment of students' native language and content area skills; (e) a lack of cohesive, comprehensive program planning; (f) insufficient offerings of content courses, and (g) a lack of materials. New curriculum frameworks and instructional strategies, adequate assessment and materials, and establishing high 
standards are components of systemic reform to address the deficient services to LEP students (August, Hakuta \& Pompa, 1994). Counseling, considered a support service, is rarely incorporated into laws created to improve services to LEP students at all educational levels.

During the past two decades the counseling literature reflects the need for counselors to be trained to meet the needs of a diversified pluralistic society (D'Andrea \& Daniels, 1991). The need for change in the counseling profession is a result of: (a) the increase of racial, ethnic, and language minority populations in the United States, (b) the acknowledgment that mental health services have failed to meet the needs of persons from different cultural, racial and ethnic backgrounds (c) the acknowledgment that most minority groups are underrepresented in conventional counseling programs, and (d) the acknowledgment that the lack of minority counselors contributes to the underutilization of counseling services by language, racial, ethnic minorities from culturally different backgrounds (D'Andrea, Daniels \& Heck, 1991; Atkinson, Morten \& Sue, 1989; Ponterotto \& Casas, 1987; Sue \& Sue, 1990).

School counseling programs are currently experiencing expansion and renewal concerning the nature and scope of services. Borders and Drury (1991) cite four core principals inherent to effective school counseling programs: (a) an independent educational program that is purposeful and sequential through a guidance curriculum that includes student competencies, program objectives, materials and resources, qualified professionals and an evaluation system, (b) an integrative program whereby guidance is 
infused into all areas of the traditional curriculum, (c) a developmental program that is proactive and preventive to help students acquire the knowledge, skills, self-awareness, and attitudes necessary for successful mastery of normal developmental tasks, and (d) an equitable program that serves all students equally such as those who are average, gifted, low achieving, handicapped and disabled, in all ethnic, cultural and sexual orientation groups, those who speak English as a second language, migrants, athletes and nonathletes, and any other "special students."

Counselors are agents for change in schools. After assessing the needs of students, whether individually or in groups, counselors establish programs to address those needs. Student needs change in response to social trends such as substance abuse, changing sexual mores, single parent families and increasing violence in the media (Monson \& Brown, 1985). Societal changes forces youth to face issues such as an accelerating crime rate, increasing dropout rates, lack of family support, neglect, and a sense of depersonalization in the schools (Horowitz, 1989). These trends impact student affect, self-esteem, and behavior. Because positive or high self-esteem and a healthy self concept are important to learning (Maeroff, 1990) school counselors become the students' advocate and show that they believe in the students as worthwhile individuals when they experience difficulties in school. The counselor is the one who can apply Roger's (1961) conditions for change--genuineness, empathetic understanding, and acceptance to fulfill the students' needs of success, belonging and involvement (Blum \& Jones, 1993). 
The role of counselors as change agents is to help clients resolve their problems and conflicts using professional techniques and activities. This is usually accomplished by exploring and utilizing the clients' personal resources (Draguns, 1990). Early research on client counseling preference revealed that racial/cultural similarities were important in establishing the counseling relationship, while more recent studies yielded mixed findings (Pedersen, Fukuyama \& Heath, 1990). Draguns (1990) explains that language minority students are often bewildered, unfamiliar and confused about counseling services offered. "Consequently, such a client does not benefit from counseling and frequently fails to return for any future appointments" (Draguns, 1990, p. 5). Pedersen, Fukuyama and Heath (1990) raise several issues as they summarize the research on matching clients and counselor: (a) the preference for counseling style may be more important than ethnic matching; (b) matching clients and counselors suggests stereotyping; (c) some minority clients will respond to matching with anger; (d) bringing in a cultural broker or mediator are more promising in bridging ethnic differences, and (e) counselors who are bilingual themselves have a great advantage.

Bilingual counselors, who speak the home language of the majority of LEP students, can help ease the transition of LEP students into the new foreign culture at school. They can serve as liaison between the student and the English speaking teachers, between the parent and the school and between the student, parent, and community resources (Keyes, 1989). Such counselors can exert a positive social influence, enhance a student's self confidence and serve as positive role models for language minority students 
(Project Assist, 1984) Their under utilization of counseling services (Negy \& Woods, 1992) and under achievement at all levels becomes a concern for counselors as they apply intervention strategies to assist them to perform better in school.

A general consensus exists among counseling professionals regarding interventions in a school counseling program (ASCA/NACAC, 1986; Glosoff \& Koprowicz, 1990). Counseling intervention strategies are classified as direct and indirect services. Direct services include individual and group counseling, and classroom guidance whereas indirect services are consultation and coordination (Borders \& Drury, 1991). Wiggins and Moody (1987) conducted a study in school rated as excellent to investigate the activities of counselors. They found that there were more direct services being provided to the students. "These results indicate that in excellent schools, counselors spend the majority of their time in counseling and counseling-related activities" (Borders \& Drury, 1991).

Improved school performance, students' personal and social growth, and educational and career development comprise the goals of a comprehensive school counseling program. Several studies indicate that academic performance was improved through counseling (Gerler, Kinney \& Anderson, 1985; Wilson, 1985). Small group counseling is cost and time efficient for students who share similar concerns. It allows participants to share coping strategies and receive feedback. (Myrick, 1987; Borders \& Drury, 1991). Studies of group counseling have shown that students improved their performance in school (Morse, 1987), attendance (Krivatsy-O'Hara, Reed \& Davenport, 
1978) self-esteem (Herr, 1982), self-concepts (Cangelosi, Gressard, \& Mines, 1980).

Classroom guidance or classroom group counseling, the most visible counseling intervention strategy, allows counselors to reach the developmental needs of larger numbers of students (Myrick, 1987).

According to Pedersen (1991) "multicultural" is "generic to all counseling relationships" (p. 7) based on a broad definition of culture that includes demographic and ethnographic variables, and affiliations. He claims that "the broad definition of culture is particularly important in preparing counselors to deal with the complex differences among clients from or between every cultural group" (Pedersen, 1991, p. 7). Besides understanding the broad definition of culture, counselors must be aware of the professional and personal limitations that influence their interactions with clients from diverse backgrounds. Casas and Vasquez (1990) provide a framework of client, counselor and counseling process variables that strongly affect the counseling of Hispanic clients. They state that the "counseling profession is anything but impartial" (p. 156) because the values of the majority culture: a white, middle class culture form the core values of the profession. These values can be in conflict with those of a Hispanic client. Ideally, counselors dealing with cultural, racial/ethnic, and language minority clients must integrate their own cultural identity with that of their client (Pedersen, Fukuyama \& Heath, 1990). Pedersen, Fukuyama and Heath (1990) conclude that client counselor matching raises several issues: (a) the preference for counseling style may be more important than ethnic matching, (b) matching clients and counselors suggests 
stereotyping, (c) some minority clients will respond to matching with anger, (d) other alternatives, such as bringing in a cultural broker or mediator, are more promising in bridging ethnic differences, and (e) counselors who are bilingual themselves have a great advantage.

LEP students who are trying to learn a new language to communicate while they attempt to live comfortably between two cultures, must deal with issues of loss, grief and readjustment (Toffoli \& Allan, 1992). However, "most ESOL curriculum materials address linguistic concerns and ignore many of the emotional issues" (Toffoli \& Allan, 1992, p. 136). Since the review of the literature revealed that there were no identifiable methods to help uprooted immigrants examine how to relinquish the past and build up for the future, Toffoli and Allan (1992) designed a group guidance program for high school LEP students. The program used guided imagery, drawing, writing and discussion to develop topics for 16 weeks of instruction. They report that the students gained selfknowledge and self-understanding as their feelings and stories were heard and acknowledged. A thorough review of the counseling and limited English proficient literature revealed that Toffoli and Allan's (1992) study is one of a kind.

Classroom group counseling is the technique that usually involves a unit of instruction based on the students' needs and interests. Several researchers have investigated the effects of classroom group counseling on classroom behavior and attitudes (Myrick, Merhill \& Swanson, 1986; Gerler \& Anderson, 1986) as well as on 
academic performance in school (Wilson, 1986). Results indicated positive changes in behavior and attitudes and higher final exam grades.

The literature on self-esteem, dropouts, and "at-risk" students, regardless of ethnicity, is intertwined with the role and function of school counselors. They are professionally trained to address the needs of the students often overlooked by teachers. Their roles are to help students with personal, educational, and career problems (Monson \& Brown, 1985), and to model as well as train teachers in communication and interpersonal skills (Rice \& Smith, 1993). The counselors' functions are to promote the development of young people to foster the learning and growth of all students, while assisting individual students to resolve special problems and concerns (Neukrug, Barr, Hoffman \& Kaplan, 1993), and help clients to reach their goals (Rice \& Smith, 1993). Summary

As the number of LEP students increases so do their needs in educational settings. As they strive to maintain their own culture while assimilating into the mainstream culture, the immigrant Hispanic LEP adolescents must reconcile the personal, social, cultural and affective conflicts they face as they balance two different cultures.

As much or more so than teachers or administrators, the school counselor is able to assist the LEP students with their problems. Teachers have instructional responsibilities. Administrators supervise faculy and staff, discipline students, and monitor programs within the school. The counselor is the trained professional who intervenes and assists with individual problems. The interactive behavior between a 
student and a counselor is extremely important. Effective counseling can help students overcome difficulties to improve their performance in school.

As a result of cultural differences in acculturation, ethnic identity and self-esteem language minority students traditionally underutilize counseling services (Casas \& Vazquez, 1991; Draguns, 1991). Students' cultural perspective of the counselor's function can trigger embarrassment and apprehension. These feelings coupled with "the belief that there is a great stigma in receiving counseling unless one is really emotionally disturbed" (Sanchez, 1981, p. 7) often inhibit language minority students from seeking a counselor's assistance. They are afraid of ridicule, indifference or criticism.

Bilingual, bicultural counselors can serve as liaison for language minority students between the student, and English speaking teachers, between the parent and the school, and among the student, parent and community (Keyes, 1989). Such counselors can exert a positive social influence, enhance a student's self confidence, and serve as positive role models for language minority students.

To summarize, dropout rates for Hispanics are higher than for Whites and African Americans. The immigrant LEP Hispanic population and its dropout rates are increasing exponentially. The advent of Bilingual Education, work-related programs and other curricular interventions attempt to meet the academic needs of immigrant LEP students in the schools. The purpose of these programs is to help academic achievement and raise the test scores of these language minority students. Research data indicate that English language proficiency is positively correlated to success in school for LEP students. 
However, there is a lack of empirical data in the counseling and language minority literature on intervention strategies and techniques that can address the needs of LEP students beyond the classroom and academics. If the academic needs are met but the personal, social and cultural problems are not addressed on a daily basis at the school sites, it may be difficult to reverse the current dropout trends. The counselor at the school site is the one who has professional and technical training to address the personal, social, and cultural conflicts of the students. For the immigrant LEP Hispanic student who is not familiar with the role and function of a school counselor in the U.S. schools, it is necessary to implement a group counseling program that reaches out to the total LEP population of a school. If the group counseling can be implemented with bilingual counselors who share the home language of LEP students, a bond may be established in the group counseling sessions. Becoming familiar with a bilingual counselor and the role, function, and services that the counselor can provide to the LEP student can make a significant difference in that student's self-esteem, attendance and counselor utilization in high school. 


\section{Chapter III}

\section{Methodology}

\section{Introduction}

This study explored the effects of group counseling on the self-esteem, attendance, and counselor utilization of immigrant Hispanic LEP secondary students at a suburban high school. As evident in the research literature, these factors are related to escalating dropout rates for this population (Chavez, Belkin, Hornback \& Adams, 1991; Gringas \& Careaga, 1989; Fenelon, Khoxayo, Kwiat \& Rodriguez, 1993; Waggoner, 1991). This section describes the methodological rationale, the population and sample of this study, the procedures, the overview of strategies, and the instrument selection.

\section{Methodological Rationale}

This study is designed as a quasi-experimental design. A quasi experimental design is used when the researcher cannot randomly assign subjects to a group and has to utilize existing classrooms (Gay, 1996). Existing English for Speakers of Other Languages (ESOL) classrooms at the designated high school were used. The purpose of the study was to investigate the effects of group counseling on the self-esteem, attendance and counselor utilization of immigrant Hispanic LEP high school students.

A nonequivalent control group design is appropriate for this study since the subjects were not randomly assigned to their current ESOL class. This design involves using two existing groups which are pretested, administered a treatment, and posttested 
(Gay, 1996). Although the students are not randomly assigned as in a random, stratified or cluster sample procedure, they are assigned to their classes via a computer program used by the school district before the school year began. During pre-registration a number of sections are opened for each required course based on the total enrollment of the school in each grade. Each section is capped at a certain number of seats so that a maximum number of students can be scheduled by the computer into each class section. During the registration process students complete a subject selection worksheet where they choose six courses based on the grade requirements and available electives. The course selections are entered into the computer program for each student, one grade level at a time. At different time intervals the computer schedules students into the six different classes chosen during registration. Students, who enter school for the first time after school is in session, are assigned to the required and elective courses based on class size. That is, the students are placed in the classes with the lowest number of students.

The control group consisted of four ESOL classes: one level I class, one level II, one level III, and one level IV. The experimental group consisted of another set of four ESOL classes, levels I through IV. Data were utilized exclusively from immigrant Hispanic students who were born outside the United States.

The treatment that the experimental group received was a weekly session of approximately 60 minutes, except when school events interfered with the scheduled session, for a period of 15 weeks, of group counseling presented by a bilingual counselor during the ESOL class period. The control group was treated as usual, that is, without 
any group counseling in their classes. The students in the control group classes continued to see any of the bilingual counselors or their assigned counselor for individual counseling in case of any academic, personal or social problem they encountered at any time.

The independent variable in this study was the personal-social skill group counseling, delivered by a bilingual counselor, that the four ESOL classes received over a period of 15 weeks. The dependent variables are self-esteem, school attendance, and counselor utilization. Self-esteem was measured using the Culture Free Self-Esteem Inventory Form AD (CFSEI-AD), (Battle, 1992) which is a pencil and paper self-report measure. Attendance was recorded from the school's computer record for each student, and counselor utilization data was obtained from Background Information Questionnaire (BIQ), which is described in the instrumentation section later in this chapter.

Acculturation level was measured by the Short Acculturation Scale for Hispanic Youth (SASH-Y),(Barona \& Miller, 1994).

\section{Population and Sample}

The study sample consisted of 112 immigrant, Hispanic (Spanish speaking) students in grades 9 through 12 enrolled in the English for Speakers of Other Languages (ESOL) program in a suburban high school in Dade County, Florida. The sample was selected from the total population of students in ESOL classes who were classified as limited English proficient (LEP) either as new or returning students. The control and experimental groups consist of four ESOL classes each, one of each language levels I-IV. 
Demographic data for the students in the experimental group $(n=61)$ indicate that their native origins were from the following countries, where Spanish is the native language: Venezuela, Puerto Rico, Cuba, Colombia, Peru, Dominican Republic, Nicaragua, Mexico, Chile, and Ecuador. In addition to the above named countries, the students in the control group $(\mathrm{n}=51)$ included natives of Guatemala. The means of students by native country in each group are presented in Table 4.

Table 4

Means of Population by Countries

\begin{tabular}{lcc}
\hline Country & $\begin{array}{c}\text { Experimental } \\
\text { Group }\end{array}$ & $\begin{array}{c}\text { Control } \\
\text { Group }\end{array}$ \\
\hline Venezuela & 2.00 & 1.75 \\
Puerto Rico & .75 & 1.25 \\
Cuba & 2.25 & 1.25 \\
Colombia & 3.00 & 2.25 \\
Peru & 1.75 & 2.25 \\
Dominican Republic & 1.25 & .50 \\
Nicaragua & .75 & .33 \\
Mexico & .25 & .00 \\
Chile & .25 & .75 \\
Argentina & .00 & .50 \\
Ecuador & .75 & 1.00 \\
Guatemala & .00 & .25 \\
\hline
\end{tabular}


The student's language level determines their ESOL class level. The language level is indicative of language proficiency in English. Incoming ninth graders have an ESOL language level obtained from any of the district approved instruments given at the middle school at the end of the previous school year. Students who were in the ESOL program during the previous school year and were returning to the school in 10 th, 11 th and 12th grades were also given a district approved language proficiency instrument at the same time as the middle school students. Students who were new to Dade County Public Schools complete a language questionnaire at the time of registration. If a student answers in a way which indicates national origin minority status, the student was assessed for English language proficiency using a district approved instrument. Based on the results of this formal assessment, a student was classified as being limited English proficient (LEP) or fluent in English. Those who are LEP have a language level ranging from one to four with one being the lowest level. ESOL class levels were assigned as follows:

$\begin{array}{cc}\text { Language Levels } & \text { Class level } \\ 1 \text { and } 2 & \text { ESOL I } \\ 2 \text { and } 3 & \text { ESOL II } \\ 3 \text { and } 4 & \text { ESOL III } \\ 4 & \text { ESOL IV }\end{array}$

Students who have language levels two, three and four, may be placed in either class level as indicated above. Class assignment depends on whether the student 
previously completed the lower of the two classes, previous academic performance, school attendance and/or the judgment of the counselor placing the student initially.

\section{Procedures}

The selected high school has seven full time counselors on its staff. Two bilingual counselors are assigned the ESOL I and ESOL II students as part of their caseload. The researcher, an immigrant Hispanic (Spanish speaking) has been working at this high school for seven years, five of those years as a counselor and for the past two years as the Dean of Students. As a counselor, with a caseload of over 500 students, the duties included individual and group counseling, consultation with parents, teachers and community agencies. As a bilingual counselor, part of the caseload included the limitedEnglish proficient (LEP) students enrolled in the English for Speakers of Other Languages (ESOL) program. In addition to doing academic, personal, and crisis counseling, collateral responsibilities included monitoring compliance with federal/state/district mandates for the ESOL program. As a counselor/dean her responsibilities included monitoring school-wide attendance and ESOL program guidelines.

The selection of the experimental and control groups was done using a random selection process. Initially four sections, one from each of the four ESOL levels, were selected to be in the control group receiving no group counseling intervention. During the second semester of the school year the researcher delivered the personal-social skills group counseling to the selected sample of students that comprise the experimental group. 
Two additional bilingual counselors delivered a similar group counseling component to the remaining ESOL classes not selected as part of the experimental group. Once a week the counselors and the researcher went to each of their classes on a designated day of the week. Four sections were selected as the experimental group using a random sampling process. The experimental group consisted of one class from each ESOL level I-IV.

\section{Data Collection}

The students were administered the instruments and completed them on site to ensure a greater rate of response of the desired population. Permission to conduct the investigation was obtained from the principal of the school.

The data collection procedure consisted of administering the Culture Free SelfEsteem Inventory (CFSEI) (Battle, 1992) and the Short Acculturation Scale for Hispanic Youth (SASH-Y) (Barona \& Miller, 1994), as pretests to the four experimental and four control group classes. All the subjects completed the Background Information Questionnaire (BIQ) at the time of the pretest. Byrne's (1989) questionnaire model was examined and modified to meet the concerns of this study. The administration of the self-report measures was conducted by the researcher.

Instructions and examples were given in English and Spanish and questions answered to clarify any ambiguity. All the limited English proficient (LEP) students were administered the instruments in their scheduled ESOL classes. The CFSEI-AD was administered to the experimental and control group subjects upon the completion of the 15 week counseling intervention. 


\section{Overview of Strategies}

Each counseling session was presented by the researcher during sessions lasting approximately 60 minutes except on occasional days when school events interfered with the schedule and the sessions were somewhat shorter. The activities utilized for the classroom group counseling sessions were selected by the researcher from the following curricula: (a) Building a Positive Self-Concept, (b) Social Skills Intervention Guide, and (c) Creative Therapy.

The activities conducted in the ESOL classes for a period of 15 weeks were as follows:

\section{Week 1: Introductions}

The counselor created pairs of students by having the group count off. Each member finds out as much as he/she can about his/her partner. Each person writes three things about their partner that are unique. Each pair comes to the front of the class and introduce each other to the group and to the counselor.

\section{Week 2: Needs Assessment}

The counselor wrote five words on the board: "Academic," "Social," "Personal," "Vocational," and "Economic." The group defined the words through a class discussion. The counselor gave examples of problems i.e., "I'm having trouble with a teacher because she doesn't like anything I do." Students matched the sample problems to the classifications on the board. The counselor asked the students to brainstorm problems they or their friends had encountered and classified them orally. The counselor gave each 
student a $3 \times 5$ index card to write down the three most pressing problems he/she was currently having. Cards were anonymous. The counselor collected them at the end of the session.

\section{Week 3: Problem Identification}

The counselor typed the problems (prior to the lesson on week 3) written by the students (on the cards) on a sheet of paper with two columns: (a) Problem for me and (b) Problem for my friends. The counselor distributed the sheets and asked the students to check the appropriate column(s) for each problem. Groups of three students were created and assigned three of the problems on the sheet of paper per group. Each group chose one of the three problems and collectively identified three strategies to deal with that problem. Each group selected a facilitator/group leader who presented their problem and solution strategies to the class. Discussion was held as necessary

\section{Week 4: Guess who is special?}

The counselor distributed a blank sheet of paper to every student. They were asked to individually write down at least three things that they are good at and/or enjoy doing. The papers were anonymous. The counselor collected the papers and redistributed them to the group. Each student read the characteristics on their sheet of paper and tried to identify the person who matched the description.

Week 5: School experience in my country

The counselor led a group discussion on the students' schooling in their homeland to include: age when they started school, the number of teachers in the school, the 
number of students in a class, the location of the school etc. Counselor then read a guided imagery script. When finished, the students were asked to illustrate a scene or image and to write a brief description about it. The students shared their pictures and stories and discussed their experience.

\section{Week 6: My first school in the United States}

Similar to activity in week 5 with a different guided imagery script. After the students illustrated their first school experience in the United States, they compared and contrasted it with their homeland school experience. They shared their comparisons with the group orally and wrote a paragraph identifying the best of their homeland school and the best of their USA school.

Week 7: What is missing from my life...?

The counselor displayed a silhouette of a window (Illustration Number 1) to the group and asked what it represented to them. The class identified this illustration as a window to the outside world. The counselor asked the students to illustrate something missing from their life that the outside world could not see. Students were asked to describe what they are missing along with their feelings. Students willing to share their illustrations with the total group did so for the remainder of the period.

\section{Week 8: The Garbage Pail}

The counselor gave two copies of the garbage pail (Handout Number 2)

illustration to each student. Discuss with the group what the garbage pail symbolizes. They were asked to focus on having the opportunity to throw something out of their lives. 
The counselor asked students to imagine throwing away something i.e., a person, an object, a place, or a feeling. Students were then asked to turn the second sheet upside down and discuss if something were being dropped from the basket into the hand.

Discuss how this could be getting something back that they had discarded in the past. Students illustrated on both sheets: something to be discarded and something to be retrieved. An oral discussion was held with the group.

\section{Week 9: My Worst and Best Experiences}

The counselor initiated a group discussion and brainstorming session of positive and negative experiences. The counselor read a guided imagery script for a negative experience. Students illustrated and wrote about their worst experience. Immediately following, the counselor read a guided imagery script of a positive experience. The students illustrated such an experience. Students volunteered to compare and contrast their worst and best experiences with the total group.

\section{Week 10: The Blank Check}

The counselor held up a picture of a blank check (Handout Number 3) and opened a discussion how a check might relate to a common fantasy. Each member of the group was given a copy of the blank check. Students filled out the check to themselves for any dollar amount they would spend for an "emotional need." They were asked identify the emotional need on the check. The counselor collected checks and redistributed them so everyone got someone else's check. Each person had to give one example of how they 
would fill that student's emotional need and then returned the check to the student whose name was on it.

\section{Week 11: "How Do I Feel"}

The counselor distributed the open-ended sentence completion worksheet (Handout number 4). The counselor and the students read the sentences out loud and clarified the meanings of sentences, offering translations when necessary. Then students completed the sentences individually. The counselor led a discussion based on the students' answers from willing participants.

Week 12: My Pluses and Minuses

The counselor distributed the worksheet (Handout number 5) with a list of adjectives. The counselor and the students read the words in unison and defined them. The students were asked to check the ones that described them individually. Students then identified how many were positive and how many were negative. The group shared responses. The counselor distributed the Mirror Worksheet (number 6) and asked students to pick from the list of words to complete the three mirrors as follows:(a) How do I see myself?, (b) how do others see me? and (c) What would I change to make others see me differently? Class discussed the individual responses as a total group.

\section{Week 13: Think It, Say It, Write It, See It}

The counselor defined the term "affirmation" for the students. An affirmation is a positive statement we tell ourselves about the achievement of our goals. Affirmations are positive, personal, specific, and in the present tense. The counselor gave an example of a 
goal, i.e,. improving an English grade, and followed with an affirmation statement for the goal. The counselor had students choose three goals: one personal, one school-related, and one home/family related. The students were asked to write a positive affirmation for each goal. Class discussion followed.

\section{Week 14: Pluses into Action}

The counselor asked the students to refer to the adjective checklist (Handout number 5) given two weeks previously. Students completed worksheet (Handout number 6) by writing two affirmation statements for each category: self, schoolwork, and others. Students shared with the total group on a voluntary basis.

Week 15: I See Me, You See Me

The counselor led a group discussion on what the students had individually learned about themselves. The counselor explored what is ideal and what is real for each one of us. Students were asked to complete worksheet (Handout number 7) and as a group discussed the their feelings about themselves, about how others see them and what they would change about themselves to change other people's perceptions.

The week after the group counseling sessions were completed the counselor administered the CFSEI-AD and an evaluation form to the experimental and control groups. Additionally, the counselor asked students to write a paragraph summarizing what they learned, what they liked best, and what they did not like about the weekly group counseling sessions. 


\section{Instrument Selection}

Background information questionnaire BIQ.

A questionnaire which elicited information about the student's

background, parent's education, attendance, perception toward school, participation in extracurricular activities and the bilingual program, and future plans. Of primary importance to this study are the questions related to the counseling services and counselor utilization by the students. Byrne's (1989) questionnaire model was examined and modified to meet the concerns of this study.

The culture free self-esteem inventory (CFSEI).

The Culture Free Self-Esteem Inventory (CFSEI) Form AD is a self-report inventory designed to measure an individual's perception of self. Form $\mathrm{AD}$ contains 40 items and is designed for use with senior high school students and adults. It can be administered to groups or individuals and yields a total selfesteem score in addition to scores in the following subtests:
(a) General self-esteem
(b) Social/peer related self-esteem
(c) Personal self-esteem

Although the CFSEI is standardized in English, each of the items is culture-free, hence the title of the instrument (Battle, 1990; 1992). "Although no instrument is completely culture-free, the CFSEI has been used effectively with 
subjects of more than 25 different ethnicities and cultures because the items represent universal feeling" (Personal communication, Battle, July, 1996). The protocols, the oral administration cassette recordings and the instrument itself have been translated into French and Spanish. Between 1981 and 1990 the three forms of the CFSEI have been translated, with the permission of the publisher, into German, Italian, Japanese and Vietnamese (Preston, 1990). The translations of the instrument "can be administered, scored, and interpreted with the same assurance of reliability and validity as the English protocols" (Battle, 1992).

The CFSEI Form AD is a valid and reliable instrument. The test-retest reliability for the CFSEI-Form Ad in the standardization sample was .79 for males, .82 for females and .81 for all subjects. A self-esteem inventory is valid if it measures one's perception of self-worth (self-esteem). Content and concurrent validity were built into the CFSEI by (a) developing a construct definition of selfesteem and (b) by writing items intended to cover all areas of the construct (Battle, 1991). Concurrent validity was established by comparing results earned on the CFSEI with the Coopersmith Self-Esteem Inventory.

The CFSEI Form AD is used for several reasons. First, the study sample consists of Spanish speaking students who are limited English proficient.

Secondly, the instrument has been translated into Spanish and used with Hispanic subjects in previous research. Finally, it has been used as a device by educators 
and mental health professionals to identify individuals in need of academic and/or psychological intervention.

\section{The short acculturation scale for Hispanic youth (SASH-Y).}

Students identified as limited-English proficient enrolled in ESOL classes were also administered The Short Acculturation Scale for Hispanic Youth (SASHY) (Barona \& Miller, 1994) The scale is a short, self-report scale that excludes socio-demographic questions and is designed to sample cultural behaviors from the context of the family as well as extrafamilial social and media influences (Barona \& Miller, 1994). It is a modification of the Short Acculturation Scale for Hispanics (Marin et al., 1987) a 12-item Likert-type scale measuring acculturation and discrimination among first and second generation of Hispanics. The results yield a composite score ranging from 12 to 60 with higher scores indicating higher acculturation to the U.S. society.

The scale measures language use as in the degree of preference participants have toward using the Spanish language. It measures the language preference of media utilized by individuals, and the ethnic self-identification based on ethnic preferences of friends and social activities. The scale was field tested and validated using a sample of 141 Hispanic and 230 non-Hispanic whites. The alpha coefficient for the total sample resulted in excellent internal consistency with an alpha coefficient of .94 . For the Hispanic sample the alpha coefficient was .92 , and for the non-Hispanic whites it was .85 . 


\section{Summary}

This study utilized a quasi-experimental design because existing classrooms were utilized. The experimental and control groups $(n=112)$ consist of four ESOL classes, one of each language level, I-IV. The four classes comprising the experimental group received group counseling once a week, for 60 minutes during 15 weeks from the researcher, a bilingual counselor. Three instruments were utilized: the Background Information Questionnaire, the Culture Free Self-Esteem Inventory Form AD, and the Short Acculturation Scale for Hispanics (SASH-Y). Analysis of the data will be presented in Chapter IV. 


\section{CHAPTER IV}

\section{Analysis of the Data}

This study was designed to answer the basic research question, "what is the effect of a group counseling program, delivered by a bilingual counselor (the independent variable), on the performance in school (the dependent variable) of immigrant Hispanic limited English proficient (LEP) secondary students?" To address the basic research question, three specific research questions comprise the core of this study. An alpha level of .05 was used for all statistical tests.

1. What is the effect of group counseling on the total, general, social and personal self-esteem of immigrant Hispanic LEP secondary students as determined by the Culture Free Self Esteem Inventory Form AD (CFSEI-AD)?

2. What is the effect of group counseling on the attendance of immigrant Hispanic LEP secondary students?

3. What is the effect of group counseling on the counselor utilization of immigrant Hispanic LEP secondary students?

Two related questions focused on the relationship of English language proficiency and acculturation to the self-esteem of the same population.

1. To what extent are differences in English language proficiency related to selfesteem? 
2. To what extent is acculturation level as measured by the Short Acculturation Scale for Hispanic Youth (SASH-Y) related to self-esteem?

It was the intent of this study to yield data helpful in identifying the impact of group counseling on the self-esteem, attendance, and counselor utilization of immigrant Hispanic LEP high school students. This chapter reviews the population, methodology, and an analysis of the research data.

\section{Analysis of the Population}

Data were collected from 112 immigrant Hispanic LEP students in grades 9 through 12 enrolled in the English for Speakers of Other Languages (ESOL) classes in a suburban high school in Dade County, Florida. The sample was selected from the total population of students in ESOL classes during the second semester of the 1995-1996 school year. Control and experimental groups were randomly selected from the sample and consisted of four ESOL classes each, one of each language level, I - IV. The 112 participants in the study were immigrant Hispanic LEP students who completed the pretest and posttest. The experimental group received group counseling treatment, once per week for 60 minutes from the researcher, a bilingual (Spanish speaking) counselor, whereas the control group received only individual counseling as necessary.

\section{Methodology}

Data collection procedures consisted of administering the Background Information Questionnaire (BIQ), the Culture Free Self Esteem Inventory Form AD (CFSEI-AD), and the Short Acculturation Scale for Hispanic Youth (SASH-Y) as pretests 
to the four experimental and four control group classes. These were administered on site by the bilingual researcher during the first week of the second semester. During the second semester of the 1995-1996 school year the bilingual researcher delivered group counseling, once a week for 60 minutes for 15 weeks, to the experimental group. The CFSEI-AD was administered to the experimental and control group subjects upon the completion of the counseling intervention as a posttest measure.

Since there was one independent and three dependent variables (self-esteem, including subtests, attendance, and counselor utilization) in this study, a multivariate analyses of variance (MANOVA) was computed to determine if there were any significant differences in the three dependent variables. Results of the MANOVA are illustrated in Table 5.

Results of the MANOVA indicate that on the variables of self-esteem, including all subtests, and attendance there were no significant differences between the experimental and control groups. There was a significant difference in the counselor use variable.

\section{Specific Research Question Number 1}

What is the effect of the group counseling on the total, general, social, and personal self-esteem of immigrant Hispanic limited English proficient secondary students? 
Table 5

Multivariate Analysis of Variance for the Four Aspects of Self-esteem. Attendance, and Counselor Utilization

Variable

df

F $\quad$ Sig of $F$

Total Self-esteem

1

.02

.90

General Self-esteem

1

.80

.37

Social Self-esteem

1

.68

.41

Personal Self-esteem

1

.14

.70

Attendance

1

.69

.41

Counselor Use

1

16.99

$* .0005$

*p>.001

\section{Data collected.}

Self-esteem pretest scores on the CFSEI-AD were collected on the participants in the experimental and control groups during the first week of the second semester. Upon completion of the 15 weeks of group counseling the experimental and control group classes completed the CFSEI-AD as a posttest measure. 


\section{Descriptive statistics.}

Results indicate that there is no significant difference in the total, general, social and personal self-esteem scores of the subjects in the experimental group versus the results of the control group. A comparison of mean scores of the total self esteem and the three subtests of self-esteem for the two groups are displayed in Table 6.

\section{Conclusion}

As indicated by the initial MANOVA (see Table 5), there were no significant differences in self-esteem scores for the participants of the experimental and control groups. As such, the group counseling intervention did not have a significant effect on the self-esteem of immigrant Hispanic LEP secondary students.

Specific Research Question Number 2

What is the effect of group counseling on the attendance of immigrant Hispanic LEP secondary students?

\section{Data collected.}

The total number of days absent from school during the first semester was recorded for each student in the experimental and control groups. Upon the completion of the 15 weeks of counseling treatment the number of days absent from September, 1995 through May 15, 1996 were recorded. These data were obtained for students from school computer records. 
Table 6

Comparison of Mean Scores on the CFSEI-AD by Group

\begin{tabular}{|c|c|c|c|c|}
\hline \multirow[b]{2}{*}{ Tests } & \multicolumn{2}{|c|}{ Pretest } & \multicolumn{2}{|c|}{ Posttest } \\
\hline & $\underline{\mathrm{M}}$ & $\underline{S D}$ & $\underline{\mathrm{M}}$ & $\underline{\mathrm{SD}}$ \\
\hline
\end{tabular}

Experimental Group $(\mathrm{n}=61)$

$\begin{array}{lcccc}\text { General } & 11.20 & 2.70 & 11.49 & 3.41 \\ \text { Social } & 6.16 & 1.45 & 6.52 & 1.56 \\ \text { Personal } & 4.56 & 2.07 & 4.54 & 2.06 \\ \text { Total } & 21.92 & 5.15 & 22.56 & 5.89\end{array}$

Control Group $(n=51)$

$\begin{array}{lcccc}\text { General } & 11.80 & 3.34 & 11.47 & 3.75 \\ \text { Social } & 5.73 & 1.55 & 6.33 & 1.63 \\ \text { Personal } & 4.57 & 2.03 & 4.55 & 2.18 \\ \text { Total } & 22.10 & 5.80 & 22.35 & 6.74\end{array}$




\section{Descriptive statistics.}

The mean number of absences for the experimental group during pretests was 5.16 , whereas the value during posttests was 5.89. The mean number of absences for the control group during pre-tests was 5.42 whereas the value during posttests was 5.70 Conclusion

Although the experimental and control groups experienced more absences after the treatment, the differences were not significant between groups (see Table 5). As such, the counseling intervention appears to not have had an effect on the school attendance of immigrant Hispanic LEP secondary students.

Specific Research Question Number 3

What is the effect of group counseling on the counselor utilization of immigrant Hispanic limited English proficient secondary students?

\section{Data collected.}

The Background Information Questionnaire (BIQ) was used for each student to identify how many times he/she had seen a counselor during the school year. Since the instrument was administered at the end of the first semester the number of counselor contacts extended from September, 1995 through January, 1996. The four choices given were: 0 times, 1-2 times, $3-4$ times, 5 or more times. After the 15 weeks of counseling treatment the students completed an evaluation questionnaire in which the same question 
was repeated. They were instructed to complete the question regarding counselor contact for the total school year from September, 1995 through May, 1996.

\section{Descriptive statistics.}

A comparison of mean scores of counselor utilization during pretests and posttests is displayed in Table 7.

The experimental group had a mean of 1.75 number of counselor contacts initially, whereas the mean value for posttest was 2.92 . The mean number of times the control group used the counselor(s) at the time of pretest was 2.09 whereas, the value at the time of the posttest was 2.59. This indicates that the experimental group had more counselor contacts after the treatment, although both groups exhibited more counselor contacts.

Results on the MANOVA, as previously noted, indicate that there was a significant difference in the number of counselor contacts between the experimental and control groups. The data in Table 8 shows a comparison of means and standard deviations of counselor utilization by level of ESOL.

\section{Conclusion}

While the degree of counselor use increased for both groups it was significantly greater for the experimental group (see Table 5). As shown on Table 8, the experimental group experienced more counselor utilization than the control group. Although not anticipated and not significant, the ESOL level 4 in the control group showed a substantial increase in counselor use. Further investigation by ESOL level indicates that 
Table 7

Comparison of Means for Counselor Utilization by Group

\begin{tabular}{lllll}
\hline & \multicolumn{2}{c}{ Pretest } & \multicolumn{2}{c}{ Posttest } \\
\cline { 2 - 4 } Tests & $\underline{\mathrm{M}}$ & $\underline{\mathrm{SD}}$ & $\underline{\mathrm{M}}$ & $\underline{\mathrm{SD}}$ \\
\hline Experimental & 1.75 & .65 & 2.92 & 1.10 \\
Control & 2.09 & .81 & 2.59 & 1.12 \\
\hline
\end{tabular}

students in the experimental group in ESOL I and II experienced the largest increase in the number of counselor contacts. The increase in the number of counselor contacts for the control group may be attributed to school events, such as the subject selection process during which students repeatedly meet with their counselor. This process occurs during the month of March at the selected high school. In summary, the data gathered to answer the three specific research questions reveal that the group counseling treatment did not have a significant effect on the personal, social, general, and total self-esteem and attendance of immigrant Hispanic LEP high school students whereas it did have a significant effect on the counselor utilization of the targeted population Relationship of English Language Proficiency Level and Acculturation to Self-Esteem

The two related questions of this study addressed the relationship of English language proficiency and acculturation to self-esteem. 
Table 8

Means and Standard Deviations of Counselor Utilization by Level of ESOL

\begin{tabular}{lllll}
\hline & \multicolumn{2}{c}{ Pretest } & \multicolumn{2}{c}{ Posttest } \\
\cline { 2 - 4 } ESOL Level & $\underline{\mathrm{M}}$ & $\underline{\mathrm{SD}}$ & $\underline{\mathrm{M}}$ & $\underline{\mathrm{SD}}$ \\
\hline
\end{tabular}

\begin{tabular}{ccccc} 
& \multicolumn{5}{c}{ Experimental Group $(\mathrm{n}=61)$} \\
I & 1.90 & .57 & 3.00 & 1.05 \\
II & 1.92 & .64 & 3.85 & .38 \\
III & 1.65 & .70 & 2.71 & .92 \\
IV & 1.67 & .66 & 2.48 & 1.25
\end{tabular}

\section{Control Group ( $\mathrm{n}=51$ )}

$\begin{array}{lllll}\text { I } & 2.00 & .55 & 1.93 & .83 \\ \text { II } & 2.17 & .94 & 2.92 & 1.24 \\ \text { III } & 1.93 & .83 & 2.43 & 1.09 \\ \text { IV } & 2.29 & .91 & 3.14 & 1.03\end{array}$




\section{Related Research Question Number 1}

To what extent is English language proficiency related to self-esteem?

A correlational analysis was done to assess the relationship between English language proficiency (ESOL level) and self-esteem scores. Correlations of ESOL level and CFSEI-AD initial scores for total self-esteem and the three subtests are illustrated in Table 9.

Table 9

Correlation of CFSEI-AD Self-Esteem Scores and ESOL

CFSEI-AD

Self-Esteem
Correlation $(r)$ with ESOL

levels

$$
(n=222)
$$

General

.05

Social

Personal

Total
.08

.03

.06

The Pearson correlation coefficient between the initial scores of the CFSEI-AD and ESOL levels indicated that English language proficiency was not related to self- 
esteem scores. The number of students $(n=222)$ includes the total number of students in the experimental and control groups who had complete data.

Further investigation of the data indicates that the total self-esteem scores of students are more positive as the English language proficiency level increases except for the ESOL level I students who had an initially higher total self-esteem score than ESOL II students. A comparison of the means of Total Self-Esteem by ESOL level is displayed in Table 10.

Table 10

Total Self-Esteem Means by Level of ESOL

\begin{tabular}{lcccc}
\hline & \multicolumn{2}{c}{ Pretest } & \multicolumn{2}{c}{ Posttest } \\
\cline { 2 - 5 } ESOL Level & $\underline{M}$ & $\underline{\text { SD }}$ & $\underline{\mathrm{M}}$ & $\underline{\mathrm{SD}}$ \\
\hline I & 19.40 & 4.30 & 18.40 & 4.01 \\
II & 18.15 & 6.85 & 19.58 & 7.40 \\
III & 20.00 & 5.73 & 22.08 & 4.82 \\
IV & 22.41 & 4.66 & 24.41 & 4.18 \\
\hline
\end{tabular}

Results of ESOL levels II, III, and IV indicate that as a general trend, although not significant, students self-esteem scores improve as they become more proficient in English. The ESOL III and IV students exhibited the greatest differences in total selfesteem scores. 
To what extent is acculturation level as measured by the Short Acculturation Scale for Hispanic Youth (SASH-Y) related to self-esteem?

A correlational analysis was conducted to assess the relationship between acculturation and total self-esteem. Correlations of SASH-Y scores and CFSEI-AD scores for self-esteem are found in Table 11.

Table 11

Correlation of SASH-Y Scores with CFSEI-AD Self-Esteem Scores

CFSEI-AD

Self-Esteem
Correlation ( $r$ ) with SASH-Y

Acculturation Scores

$$
(\mathrm{n}=134)
$$

General

Social .04

Personal

$-.002$

Total .02

The Pearson correlation coefficient between these two variables revealed no significant relationship between them for participants in the study. The number of 
students $(n=134)$ was larger than the number of students in the experimental and control groups since the SASH-Y was administered at the time of the pretest and many students moved and did not finish the school year at the data collection site.

\section{$\underline{\text { Summary }}$}

Data analysis indicate that group counseling delivered by a bilingual counselor did not have a significant effect on the total, general social and personal self-esteem scores and school attendance of immigrant Hispanic LEP secondary students. It did have a significant effect on the dependent variable of counselor utilization. Further investigation revealed that within the experimental group the increase in the number of counselor contacts was greater for beginning ESOL students in levels I and II than for the intermediate and advanced students in levels III and IV.

Results indicate that the self-esteem scores are not related to English language proficiency level. However, total self-esteem scores improved as the level of English proficiency increased, except for students in ESOL level I. The pretest scores for ESOL I could be a random result. Findings revealed that there was no relationship between selfesteem and acculturation. 


\section{Chapter V}

\section{Conclusions and Recommendations}

Introduction

The purpose of this study was to determine if group counseling had an effect on the self-esteem, attendance, and counselor utilization of immigrant Hispanic limited English proficient (LEP) students. In addition, it examined if English language proficiency and acculturation were related to self-esteem. This chapter will include a summary of the research study, conclusions regarding the results of the data analyses and recommendations for further research and practice.

\section{Summary of the Study}

Escalating dropout rates, failure in school, and the underutilization of counseling services by immigrant Hispanic limited English proficient (LEP) secondary students create a need to examine the effect of group counseling, delivered by a bilingual counselor, on the self-esteem, attendance and counselor use of this population. LEP students are classified as "at risk" and placed on the dropout prevention profile in every Dade County Florida Public School. Being LEP enrolled in English for Speakers of Other Languages (ESOL) is one of the seven risk factors in the district. The research literature on "at risk" language minority populations identifies other factors, besides English proficiency, that impact their performance in school such as excessive absences, low selfesteem, acculturation and a plethora of personal, social, and cultural problems. While 
adequately describing the problems, the literature does not provide an adequate account of intervention strategies that can be implemented at school sites using existing resources.

The role of counselors in schools is to address the affective needs of students so that they may perform to their maximum potential academically, socially, and personally. The function, role and services provided by counselors are foreign to immigrant Hispanic LEP students since their cultures and schools do not have counselors as in U.S. schools. Besides their lack of familiarity, this population traditionally underutilizes professional counseling services because of cultural and linguistic differences between students and staff members.

This quasi-experimental study examined the effect of group counseling, the independent variable, on self-esteem, attendance and counselor utilization, the dependent variables. The treatment, group counseling, was delivered by the researcher, a bilingual counselor, to the experimental group once per week, for 60 minutes, over a period of 15 weeks. The experimental and control groups consisted of four levels of ESOL classes, IIV.

The objective of this study was achieved by answering the basic research question, "what is the effect of a group counseling program, delivered by a bilingual counselor, on the performance in school of immigrant Hispanic limited English proficient students?" To answer the basic research question, three specific research questions and two related research questions served as the framework of this study. They are presented 
in the next section. Related research questions addressed the relationship of English language proficiency and acculturation to self-esteem.

In order to address these research questions, three self-report measures were administered. First, the Background Information Questionnaire (BIQ) elicited demographic information, participation in school activities, and counselor utilization. Second, the Culture Free Self-Esteem Inventory Form AD (CFSEI-AD) developed by Battle (1992), is a self-report inventory that yields scores in four dimensions of selfesteem: Total, General, Social and Personal. The Spanish translation was utilized with the targeted population. Third, the Short Acculturation Scale for Hispanic Youth (SASHY) developed by Barona and Miller (1994), also a self-report measure, determined the level of acculturation for each participating subject.

Given the purpose and scope of this study, two limitations must be understood. First the study was limited to one suburban high school in Dade County, Florida. The second limitation was that attrition due to mobility, transfers and withdrawals limited the sample size with complete data.

The remainder of this chapter presents each question of the study followed by pertinent findings and recommendations.

\section{Specific Research Question \# 1}

What is the effect of group counseling delivered by a bilingual counselor on the total, general, social and personal self-esteem of immigrant Hispanic limited English proficient (LEP) secondary students? 
As reported on the Culture Free Self-Esteem Inventory Form AD (CFSEI-AD) in the four dimensions of self-esteem (total, general, social and personal), data collected on 61 students in the experimental group and 51 students in the control group indicated that the effects of group counseling were not statistically significant. Although both groups experienced more positive total self-esteem scores, the changes were not statistically significant. The general self-esteem scores revealed that the experimental group experienced more positive results whereas the control group had lower general selfesteem results, but these shifts were not statistically significant. As for the social selfesteem scores, both groups experienced more positive scores. The change within the control group was statistically significant. This significant change was not a treatment effect, but a random event. Lastly, results indicate that both groups experienced lower personal self-esteem scores but the losses were not statistically significant.

\section{Specific Research Question \#2}

What is the effect of group counseling, delivered by a bilingual counselor, on the attendance of immigrant Hispanic limited English proficient (LEP) secondary students?

An analysis of the students' school absences at the time of the pretest and posttest indicate that both groups experienced more absences. The increase in absences was not statistically significant between groups. Thus, the answer to the specific research question number two is that group counseling, by a bilingual counselor, appears not to have an effect on the attendance of immigrant Hispanic LEP secondary students. 


\section{Specific Research Question \#3}

What is the effect of group counseling, delivered by a bilingual counselor, on the counselor utilization of immigrant Hispanic limited English (LEP) secondary students?

Results of data analysis indicate that the differences in counselor contact were statistically significant for the targeted population. Although not anticipated, the control group experienced a significant increase in the number of counselor contacts as a result of school events that take place in the second semester. Therefore, the answer to the specific research question number three is that the group counseling did have a significant effect on the counselor utilization of immigrant Hispanic LEP secondary students.

In addition to the three specific research questions, two related questions were part of the study.

\section{$\underline{\text { Related Question \# } 1}$}

To what extent are the differences in English language proficiency related to selfesteem?

Correlational analysis revealed that there was no relationship between English language proficiency and self-esteem scores. However, the total self-esteem pretest and posttest scores of the students in ESOL levels II, III and IV were more positive as the English language proficiency increased. The beginning level, ESOL I, participants were the exception, as their mean pretest score was initially more positive than the mean score for ESOL level II. The ESOL levels III and IV students exhibited the greatest difference 
in total self-esteem scores. These results indicated that self-esteem scores tend to improve as the students' English language proficiency increased.

\section{Related Question \#2}

To what extent is acculturation level as measured by the Short Acculturation Scale for Hispanic Youth (SASH-Y) related to self-esteem?

Correlational analysis indicated that there was no relationship between the acculturation and self-esteem scores for the participants in this study.

\section{Conclusions}

Group counseling delivered by a bilingual counselor was not statistically significant in raising the self-esteem scores of immigrant Hispanic limited English proficient (LEP) secondary students. The treatment was administered weekly for 60 minutes per session for 15 weeks. Approximately one third of the initial population of the experimental group was lost as a result of one of the following factors: (a) student and family relocated, (b) illness, (c) student transferred to another school, and (d) student withdrew from school to go to work full-time.

Group counseling did not have a significant effect, positive or negative, on the students' school attendance. It did have a statistically significant effect on counselor utilization for the targeted population. An analysis of results by ESOL level, or English language proficiency revealed that the increases in counselor contacts within the experimental group for students in ESOL levels I and II was greater than the differences in counselor contacts for ESOL levels III and IV. Conversely, students in the control 
group ESOL level I, not receiving weekly group counseling treatment, experienced a decline in the number of counselor contacts. This finding is significant, as most immigrant Hispanic limited English proficient (LEP) secondary students are not familiar with the role and function of school counselors. This is especially true of the students who are current immigrants to the United States and are not functional in the English language. It appears as a result of group counseling in the ESOL classes once a week, a larger number of students had the opportunity to understand the role, function and services of a counselor in a non-threatening environment. Once the students became familiar with a bilingual counselor, their fears and apprehensions decreased and they felt more comfortable to seek counselor assistance for their academic, personal, and social problems.

Group counseling did not have a significant effect on the subjects school attendance. Both groups experienced an increase in absences. Relevant to this issue is the fact that the mean number of days absent for the experimental and control groups increased by less than one day, from 5.16 to 5.89 and from 5.42 to 5.70 respectively, from the time of the pre-intervention to post-intervention.

These findings support a study done in a large urban high school in Canada by Watt and Roessingh (1994). Their findings indicated proficiency in English was the most powerful predictor of success for LEP students. That is, students in ESOL levels III and IV had an $86 \%$ graduation rate. They concluded that the overall dropout rate for the sample of 232 LEP students was 74\% (Watt \& Roessingh, 1994). Since the intermediate 
and advanced (ESOL III and IV) LEP students achieved such a high graduation rate, then the students in lower levels (ESOL I and II) comprise the largest number of dropouts. It appears then that the students who utilized counselors significantly more as a result of the counseling treatment in this study (ESOL levels I and II) are the same level of students who comprise the group most likely to dropout. This study documented that ESOL students in levels I and II, once they became familiar with the role and function of school counselors, utilized their services more. As newcomers, in most cases, they were unaware of the services available to them at their school site.

Both in the findings of the Watt and Roessingh (1994) study, and the results of this study affirm that as English language proficiency increases so does the gain in selfesteem. This means that as LEP students experience gains in English language proficiency and self-esteem they have a better probability of improving their school performance and graduating from high school. Conversely, students in the lower levels of English language proficiency (ESOL I and II), who experienced slight or no gain in their self-esteem scores utilized more counseling services once they became familiar with the role and function of counselors through classroom group counseling.

\section{Recommendations for Further Research}

1. Do a comparative study using weekly group counseling, delivered by bilingual counselors, to examine the differences between other language minority populations i.e., Haitians, Asians. 
2. Replicate this study with elementary and/or middle school students to examine and compare if there is a difference in the results by age groups.

3. Do a comparative study utilizing counselor client match by national origin, e.g., Nicaraguan/Nicaraguan versus a counselor/client match by language only to determine if national origin makes a difference in the results.

\section{Recommendations for Practice}

1. Extend group counseling services by bilingual counselors at the high school level for selected populations, i.e., ESOL levels I and II.

2. Provide inservice and preservice training for counselors on cultural, linguistic and ethnic minority populations so they will be more aware and sensitive to their needs.

3. Extend counselors' awareness of their own multicultural sensitivity through inservice training, relocation to another school with a different ethnic composition during summer school, and having counselors complete multicultural awareness instruments.

4. Initiate counselor directed sessions in the evening, on a monthly basis, as well as outreach programs, for the parents of LEP students to familiarize families with the services, including counseling, available at the school site.

5 Establish a professional library at the school site with multicultural literature for teachers to use. An understanding of the needs of language and ethnic minority students will result in better services to these populations. 
6. Provide training for ESOL teachers on counseling strategies and guidance materials so they will be able to lead group counseling sessions when bilingual counselors are not available in their school.

7. Provide training for administrators on the need for counseling intervention for ESOL students, specifically for those in the entry level classes.

8. Revise counselor preservice programs to focus on the needs of the immigrant Hispanic LEP population.

\section{Conclusion}

As we approach the turn of the century, the one thing we can count on is change. The population shifts in schools mirror the demographic changes that society is experiencing. It is important that educators, policymakers, and researchers implement new strategies to reach the increasing numbers of "at risk" students. Societal, familial and cultural changes imply that students, specifically adolescents, face a multitude of personal, social, and academic problems that hinder their successful performance in school.

Findings of this study indicate that students in the lower levels of ESOL, I and II, need counseling services and will utilize the services available once they become familiar with the role and function of school counselors. It is hoped that the results of this study will improve services for a population that greatly needs the assistance of a professional school counselor. 


\section{References}

Alberta Education. (1992). Achieving the vision report. Edmonton, AB: Author.

Arias, M. (1986). The context of education for Hispanic students: An overview. American Journal of Education 95, 26-57.

August, D., Hakuta, K., \& Pompa, D. (1994). For all students: Limited English proficient students and goals 2000. Washington D.C.: National Clearinghouse for Bilingual Education, FOCUS No. 10.

Arredondo, P. (1986, May). Immigration as a historical moment leading to an identity crisis. Journal of Counseling and Human Service Professions. 79-87.

Barona, A., \& Miller, J. A. (1994). Short acculturation scale for Hispanic youth (SASHY): A preliminary report.

Baratz-Snowden, J., Rock, D., Pollack, J., \& Wilder, G. (1988). The educational progress of language minority children: Findings from the NAEP 1985-1986 study. Princeton, NJ: National assessment of Educational Progress- Educational Testing Service.

Battle, J. (1992). Culture-free self-esteem inventories. (2nd ed.). Austin, TX: Pro-ed. Battle, J. (1994). Promoting self-esteem, achievement and well being: An effective instructional curriculum for all levels. Edmonton, Alberta: James Battle and Associates Ltd.

Battle, J. (1990). Self-esteem: The new revolution. Edmonton, Alberta: James Battle and Associates Ltd. 
Beck L., \& Muia, J. A. (1980) A portrait of a tragedy. Research findings on the dropout. High School Journal, 21, 65-72.

Bernal, M. E., Saenz, D. S., \& Knight, G. P. (1991). Ethnic identity and adaptation of Mexican American youths in school settings. Hispanic Journal of Behavioral Sciences, 13. (2), 135-154.

Berry, J. W. (1980). Social and cultural change. In H.C. Triandis (Ed.), Handbook of Cross Cultural Psychology: Volume 5. (p. 211-279) Boston: Allyn and Bacon.

Berry, J., Kim, U., Minde, T., \& Mok, D. (1987). Comparative studies of acculturative stress. International Migration Review, 21, 491-511.

Berry, J., Kim, U., Power, S., Young, M., \& Bujaki, J. (1989). Acculturation attitudes in plural societies. Applied Psychology, 38, 185-206.

Blum, D.J., \& Jones, A. A. (1993). Academic growth group and mentoring program for potential dropouts. The School Counselor.40, 207-212.

Borders, L. D., \& Drury, S. M. (1992). Comprehensive school counseling programs: A review for policymakers and practitioners. Journal of Counseling and Development, 70, 487-498.

Bowler, R., Rauch, S., \& Schwarzer, R. (1986). Self-esteem and interracial attitudes in black high school students: A comparison with five other ethnic groups. Urban Education, 21, (1). 3-19. 
Borders, L. D., \& Drury, S. M. (1992). Comprehensive school counseling programs: A review for policymakers and practitioners. Journal of Counseling and Development $(70), 487-497$.

Branden, N. (1990). What is self-esteem? (ERIC Document Reproduction Service No. ED 325763$)$.

Braught, S. (1992). The school counselor as consultant on self-esteem: An example. Elementary School Guidance and Counseling, 26, (3), 229-236.

Bull, K. S. (1991). Minority dropouts: Do rural, urban, and suburban administrators perceive causes affecting minorities as priority items? (ERIC Reproduction Service No. ED 342 553).

Byrne, A. D. (1989). Factors affecting the academic success of Native American students who attend a public high school in southern California (Doctoral dissertation, Northern Arizona University, 1989)). Dissertation Abstracts International, 8917944.

Careaga, R. C. (1988, Fall). Keeping limited English proficient students in school: strategies for dropout prevention. National Clearinghouse for Bilingual Education. (7). 1-20.

Carter, T. P. (1968). Negative self-concepts of Mexican-American students. School and Society, 96, 217-219. 
Casas, J. M., \& Vasquez, M.J.T. (1990). Counseling the Hispanic client: A theoretical and applied perspective. In P. Pedersen (Ed.), Counseling Across Cultures (pp. 153-173). Hawaii: University Press.

Chapa, J., \& Valencia, R. R., (1993, May). Latino population growth, demographic characteristics, and educational stagnation: An examination of recent trends. Hispanic Journal of Behavioral Sciences. 15(2). 165-187.

Chapman, J. W., Cullen, J. L., Boersma, F. J. \& Macguire, T. O. (1981). Affective variables and school achievement: A study of possible causal influence. Canadian Journal of Behavioral Sciences, 13.

Chavez, R. C., Belkin, L. D., Hornback, J. G., \& Adams, K. (1991). Dropping out of school: Issues affecting culturally, ethnically, and linguistically distinct student groups. The Journal of Educational Issues of Language Minority Students,8, 121.

Chavira, V., \& Phinney, J. S. (1991). Adolescents' ethnic identity, self-esteem, and strategies for dealing with ethnicity and minority status. Hispanic Journal of Behavioral Sciences, 13.(2), 226-227.

Children's Defense Fund. (1991). The state of America's children. Washington, D.C.: Children's Defense Fund.

Clement, R. (1986). Second language proficiency and acculturation: An investigation of the effects of language status and individual characteristics. Journal of Language and Social Psychology 5(4), 271-290. 
Collier, V. (1995). Acquiring a second language for school. National Clearinghouse for Bilingual Education, NCBE, Directions, 1,(4), 1-11.

Combs, J., \& Colley, W. W. (1968). Dropouts: In high school and after high school. American Educational Research Journal,5. (3), 343-363.

Coopersmith, S. (1981). SEI: Self-esteem Inventories. Palo Alto: Consulting Psychologists Press.

Crocker, J., \& Major, B. (1989). Social stigma and self-esteem: The self-protective properties of stigma. Psychological Review, 96, 608-630.

Crosby, E. A. (1993). The 'at-risk' decade. Phi Delta Kappan, 598-604.

Cross, W. (1978). The Thomas and Cross models of psychological nigrescence: A literature review. Journal of Black Psychology.4, 13-31.

Cuellar, I., Harris, L.C., \& Jasso R. (1980). An acculturation scale for MexicanAmerican normal and clinical populations. Hispanic Journal of Behavioral Sciences, 2, 199-217.

de la Rocha-Petris, G. (1980). Chimextla Project. A summary report on educational needs of Latinos: County of San Mateo. San Mateo, CA. (ERIC Document Reproduction Service No. ED 188674 )

Dade County Public Schools (DCPS). Office of Educational Accountability. (1994). Annual cross-sectional dropout/truant rates for 1992-1993.

Dade County Public Schools (DCPS). Office of Educational Accountability. (1994) Longitudinal dropout/truant rates. 
Delgado-Gaitan, C. (1988). The value of conformity: Learning to stay in school. Anthropology and Education Quarterly, 19, (4), 354-381.

Dona, G. (1991, May). Acculturation and ethnic identity of Central American Refugees in Canada. Hispanic Journal of Behavioral Sciences, 13.(2), 230-231.

Dougherty, V. (1991). Youth at risk: The need for information. In J. M. Lakebrink, (ed.) Children at Risk. (pp. 3-17) Springfield, IL: Charles C. Thomas Publisher. Dougherty, V. (1987) Youth at risk, the first step: Understanding the data. Denver: The Education Commission of the States.

Doyle, D. (1987). A selected literature review on the present status of Hispanics and Mexican Americans with an emphasis on student educational outcomes. Hispanic Journal of Behavioral Sciences, $9,5-13$.

Draguns, J. G. (1990). Dilemmas and choices in cross-cultural counseling: The universal versus the culturally distinctive. In P. Pedersen (Ed.). Counseling AcrosS Cultures (pp. 3-21). Hawaii: University Press.

Educational Research Service. (1995, January). Demographic Factors in American Education. (ERIC Document Reproduction Service No. ED 379 773) Ekstrom, R. B., Goetz, M.E., Pollack, J. M., \& Rock, D.A. (1986,). Who drops out of high school and why? Findings from a national study. Teachers College Record, (87). 393-409.

Fenelon, J., Khoxayo, P., Kwiat, J. A., \& Rodriguez, B. (1993). Counseling culturally and linguistically diverse students. 11 linois School Journal,72, 1532 
Fernandez, R. M., \& Paulsen, R. (1989). Dropping out among Hispanic youth. Social Science Research, 18, 21-52.

Fernandez, R. R., \& Velez, W. (1989). Who stays? Who leaves: Findings from the ASPIRA Five Cities High School Dropout Study. Washington DC: ASPIRA Association, Inc. (ED 322 241))

Fine, M., \& Rosenberg, P. (1983). Dropping out of high school: The ideology of school and work. Journal of Education. 165, 257-272.

Fleischman, H. L., \& Hopstock, P. J. (1993). Descriptive study of services to limited English proficient students. Arlington, VA: Development Associates, Inc.

Florida State Legislature. (1987). Student Services Act 230.2313, 71-73.

Frazer, L., \& Nichols, T. (1991). At-risk report:: 1990-1991: Executive summary. Austin, TX: Austing Independent School District, Office of Research and Evaluation. (ERIC Reproduction Service No. ED 338789.

Friedenberg, J. E., \& Izzo, M. V. (1993). A proposed intervention model for serving atrisk limited-English- proficient youth with disabilities. Journal of Industrial Teacher Education, 30, (2). 81-99.

Garcia, M., \& Lega, L. (1979). Development of a Cuban ethnic identity questionnaire. Hispanic Journal of Behavioral Sciences, 1, 247-261.

Gastright, J. F. (1989, April). Don't base your dropout program on somebody else's problem. Phi Delta Kappa Research Bulletin(8). 1-4.

Gay, L. (1996). Educational Research (5th ed.), New York: Prentice-Hall. 
George, J. D. (1992). The school dropout problem: A pilot project. Guidance and Counseling, 8 (2), 36-44.

Gibson, R. L. (1990). Teachers' opinions of high school counseling and guidance programs: Then and now. The School Counselor, 37, 248-255.

Grannis, J. C. (1991, February). Meeting the goals of school completion. Clearinghouse on Urban Education Digest Bulletin.(69), 3-4.

Gingras, R. C., \& Careaga, R. C. (1989, Spring). Limited English proficient students at risk: Issues and prevention strategies. New Focus. National Clearinghouse for Bilingual Education: 1-11.

Grossman B., Wirt, R., \& Davids, A. (1985 Self-esteem, ethnic identity, and behavioral adjustment among Anglo and Chicano adolescents in West Texas, $\underline{\text { Journal of }}$ Adolescence, 8, 57-68.

Hamachek, D. E. (1987), Encounters with the self (3rd ed.). New York: Holt, Rinehart and Winston.

Henderson, A. et al. (1994). Summary of the bilingual education state education agency program survey of states 'limited English proficient persons and available educational services 1992-1993. Arlington, VA: Development Associates, Inc. Hinojosa, D., \& Miller, L. (1984). Grade level attainment among migrant farm workers in south Texas. The Journal of Educational Research.77.(6), 346-350.

Hopstock, P., \& Bucaro, B. (1993). A review and analysis of estimates of LEP student population. Arlington, VA: Development Associates, Inc. 
Johnson, D. S. (1981). Naturally acquired learned helplessness: The relationship of school failure to achievement behavior attributions and self-concept. Journal of Educational Psychology, 73 , 174-80.

Jones, E. F. (1985). Age at immigration and education: Further explorations. International Migration Review, 21.(1), 70-85.

Kaufman, P., \& Frase, M. J. (1990). Dropout rates in the United States: 1989. (Office of Educational Research and Improvement Report No. NCES 9-659). Washington, DC: U.S. Department of Education.

Keyes, K. L. (1989). The counselor's role in helping students with limited English proficiency. The School Counselor, 37, 144-148.

Kohn, A. (1994). The truth about self-esteem. Phi Delta Kappan, 76.(4). 272-283 Kyle, C. L. (1984). Los preciosos: The magnitude of and reasons for the Hispanic dropout problem in Chicago: A case study of two Chicago public high schools. Unpublished doctoral dissertation. Northwestern University, Evanston, IL. Lakebrink, J. M. (1989). Children at risk. Springfield, Illinois: Charles C. Thomas. Lang, J., Munoz, R., Bernal, G., \& Sorenson, J. (1982). Quality of life and psychological well-being in a bicultural Latino community. Hispanic Journal of Behavioral Sciences, 4, 433-450.

Larned, D. D., \& Muller, D. (1979). Development of self-concept in Mexican-American and Anglo students. Hispanic Journal of Behavioral Sciences, 1, 279-285. 
Larsen, P., \& Shertzer, B. (1987). The high school dropout: Everybody's problem. The School Counselor. 163-169.

Lewis, A. C. (1992). Student motivation and learning: The role of the school counselor. The School Counselor, 39, 333-337.

Lucas, T. (1993). Applying elements of effective secondary schooling for language minority students: A tool for reflection and stimulus to change. National Clearinghouse for Bilingual Education Program Information Guide Series, No.14. Washington DC: George Washington University.

Lucas, T., Henze, R., \& Donato, R. (1990). Promoting the success of Latino language minority students: An exploratory study of six high schools. $\underline{\text { Harvard }}$ Educational Review, 60,(3). 315-340.

Maeroff, G. I. (1988). Withered hopes, stillborn dreams: The dismal panorama of urban schools. Phi Delta Kappan, 69, (9), 632-638.

Marin, P. V. (1990). Graduating and dropping out of high school in the South Bronx. New York, NY: City University of New York. (ERIC Reproduction Service No. $358078)$.

Maruyuma, G., Rubin, R., \& Kingsbury, G. G. (1981). Self-esteem and educational achievement: Independent constructs with a common cause? Journal of Personality and Social Psychology, 40, 962--975.

Maslow, A. H. (1970). (2nd ed). Motivation and personality. New York: Harper Row Publishers, Inc. 
Matute-Bianchi, M. E. (1986). Ethnic identity and patterns of school success and failure among Mexican-descent and Japanese -American students in a California High school: An ethnographic analysis. American Journal of Education 95, 233-255.

McCarthy, K., \& Gombert, J. (1985). Current and future effects of Mexican immigration in California. Monograph $(\mathrm{R}-3365 / 1-\mathrm{CR})$, Santa Monica, California: Rand Corporation.

McMillen, M. M. Dropout rates in the United States: 1992. (ERIC Reproduction Service No. ED 363 671).

Minicucci, C. (1992). Programs for secondary limited English proficient students: A California study. Washington, DC: National Clearinghouse for Bilingual Education.

Monson, R. J., \& Brown, D. (1985). Secondary school counseling: A time for reassessment and revitalization. National Association of Secondary School Principals (NASSP) Bulletin, 32-35.

Myrick, R. D., Merhill, H., \& Swanson, L. (1986). Changing student attitudes through classroom guidance. The School Counselor. 33, 244-252.

National Clearinghouse for Bilingual Education, NCBE. (1989). Reducing dropout among LEP students. 1-7.

National Clearinghouse for Bilingual Education, NCBE. (1995, Fall). The changing face of America's schools. 1-7. 
Natriello, G., Pallas, A., McPartland, J., McDill, E., \& Royster, D. (1984, April). An examination of the assumptions and evidence for alternative dropout prevention programs in high school. Paper presented at the annual meeting of the American Education Research Associates, New Orleans, LA.

Negy, C., \& Woods, D. J. (1992). The importance of acculturation in understanding research with Hispanic-Americans. Hispanic Journal of Behavioral Sciences, 14.(2), 224-247.

Ochoa, A.M., Hurtado, J., Espinosa, R., \& Zachman, J. (1987). The empowerment of all students: A Framework for the prevention of school dropouts. San Diego: Institute for Cultural Pluralism, San Diego State University. Office of Bilingual Education and Minority Languages Affairs (OBEMLA), U.S. Department of Education. (1992). The condition of bilingual education in the nation: A report to the congress and the president. Washington, DC: U.S. Department of Education, Office of the Secretary.

Omizo, M.M., Hammet, V.L., \& Loffredo, D.A. (1981). The Dimensions of SelfConcept (DOSC) as predictors of academic achievement among MexicanAmerican junior high school students. Educational and Psychological Measurement, 4, 835-842.

Pantin, R. L. School counselors' time: Where does it go? The School Counselor, 40. 274-281. 
Papagiannis, G., Bickel, R., \& Fuller, R. (1983), The social creation of school dropouts: Accomplishing the reproductions of an underclass. Youth and Society, 14, 363391.

Parham, T., \& Helms, J. (1985). Attitudes of racial identity and self-esteem of black students: An exploratory investigation. Journal of College Student Personnel. 26. 143-147.

Parkes, C. M. (1971). Psycho-social transitions: A field for study. Social Science and Medicine, 5, 101-115.

Paul, M., \& Fischer, J. (1980). Correlates of self-concept among Black early adolescents. Journal of Youth and Adolescence, $9,163-173$.

Pedersen, P. B. (1989). Developing multicultural ethical guidelines for psychology. International Journal of Psychology, 24, 643-652.

Pedersen, P. B. (1991). Multiculturalism as a generic approach to counseling. Journal of Counseling and Development. 70, (1), 6-12.

Pedersen, P. B., Fukuyama, M., \& Heath, A. (1990). Client, counselor, and contextual variables in multicultural counseling. In P. Pedersen (Ed.), Counseling Across Cultures (pp. 23-52). Hawaii: University Press.

Peng, S. S. (1985). High school dropouts: A national concern. Washington, DC: National Center for Education Statistics, U.S. Department of Education. Pedersen, P. B. (1990). The multicultural perspective as a fourth force in counseling. Journal of Mental Health Counseling. 12(1), 93-95. 
Perez Miller, A. (1989). Student characteristics and persistence/dropout behavior of Hispanic students. In J. M. Lakebrink, (ed.) Children at risk. (pp. 119-139). Springfield, IL: Charles C. Thomas Publisher.

Phinney, J. (1991). Ethnic identity and self-esteem: A review and integration. Hispanic Journal of Behavioral Sciences, 13, (2), 193-208.

Phinney, J., \& Alipuria, L. (1990). Ethnic identity in college students from four ethnic groups. Journal of Adolescence, $13,171-183$.

Phinney, J., Williamson, L., \& Chavira, V. (1990, April). Attitudes towards integration. assimilation, and separation among high school and college students. Paper presented at the Western Psychological Association Meeting, Los Angeles.

Ponterotto, J.G., \& Casas, J.M. (1987). In search of multicultural competence within counselor education programs. Journal of Counseling and Development. 65,430 434.

Pottebaum, S. M., Keith, T. Z., \& Ehly, S. W. (1986). Is there a causal relation between self-concept and academic achievement? Journal of Educational Research, 79.(3), 140-144.

Powers, S., \& Sanchez, V. (1982). Correlates of self-esteem of Mexican-American Adolescents. Psychological Reports, 51, 771-4.

Project Assist. Counseling, communication and instruction. Placement procedures handbook. Oxnard, CA: Title VII Demonstration Project 1981-1984. (ERIC Document Reproduction Service No. 259 050). 
Purkey, W. (1988). An overview of self-concept theory for counselors. (ERIC

Document Reproduction Service No. ED 304 630).

Radwanski, G. (1987). Ontario study of the relevance of education and the issue of dropouts. Toronto: Ontario Ministry of Education.

Reasoner, R. W. (1992). Problem: You can bring hope to failing students. What's behind self-esteem programs: Truth or trickery? School Administrator, 49 (4), 23-26.

Reducing school dropout among LEP students. (1989). National Clearinghouse for Bilingual Education: Forum, 12, (5), 1-7.

Reyes, O., \& Jason, L. A. (1993). Pilot study examining factors associated with academic success for Hispanic high school students. Journal of Youth and Adolescence.22.(1), 57-71.

Reyes, P. (1989). Factors that affect the commitment of children at risk to stay in school. In J. M. Lakebrink, (ed.), Children at Risk (pp. 18-31). Springfield, IL: Charles C. Thomas Publisher.

Rice, G. E., \& Smith, W. (1993), Linking effective counseling and teaching skills. The School Counselor, 40, 201-206.

Roderick, M. (1995, December). Grade retention and school dropout: Policy debate and research questions. Phi Delta Kappan Research Bulletin. 15, 1-3.

Rogers, C. (1961). On becoming a person. Boston: Houghton Mifflin. 
Rogler, L. H., Cortes, D. E., \& Malgady, R. G. (1991). Acculturation and mental health status among Hispanics: Convergence and new directions for research. American Psychologist.46, 585-597.

Rong, X., Preissle-Goetz, J. (1990). High school drop-outs among foreign-born Whites, Hispanics and Asians. Paper presented at the American Education Research Association, Boston, MA.

Rosenberg, M. B. (1986). Making a new home in America. New York: Lothropp Lee \& Shepard Books.

Rotheram-Borus, M. J. (1990). Adolescents reference-group choices, self-esteem and adjustment. Journal of Personality and Social Psychology.59.(5), 1075-1081.

Rumbaut, R. G., \& Cornelius, W. A. (Eds.). (1995) California's Immigrant Children. San Diego: Center for U.S.-Mexican Studies.

Rumberger, R. W. (1987). High school dropouts: A review of issues and evidence. Review of Educational Research, 37, 101-121.

Sanchez, A. (1981). Counseling the bilingual student. Ann Arbor, MI: ERIC Clearinghouse on Counseling and Personnel Services. (ERIC Document Reproduction Service No. ED 214 050).

Sabogal, F., Marin, G., Otero-Sabogal, R., Marin, B., \& Perez-Stable, E. (1987). Hispanic familism and acculturation: What changes and what doesn't? Hispanic Journal of Behavioral Sciences, 9, 397-412. 
Shannon, S. M., \& Kakuta, K. Challenges for limited English proficient students and the schools. (1991). In M. C. Wang, M. C. Reynolds, H. J. Walberg (Eds.), Handbook of special education: research and practice. Vol. 4: Emerging programs. Advances in education (215-233) Oxford, England: Pergamon Press, Inc.

Sears, S. J. (1993). The changing scope of practice of the secondary school counselor. The School Counselor.40, 384-388.

Sodowsky, G. R., \& Plake, B. S. (1992). A study of acculturation differences among international people and suggestions for sensitivity to within-group differences. Journal of Counseling and Development. 71, (1), 53-59.

Steinberg, L., Lin Blinde, P., \& Chan, K. (1984). Dropping out among language minority youth. Review of Educational Research, 54, (1), 113-132.

Strassburger, L. A., Rosen, L. A., Miller, C. D., \& Chavez, E. L. (1990). Hispanic-Anglo differences in Academic Achievement. School Psychology International, 11, 119124.

Suarez-Orozco, M. M. (1987). Hispanic Americans: Comparative considerations and the educational problems of children. International Migration Review.25,(2), 141-163.

Sue, D. W. (1992). The challenge of multiculturalism: The road less traveled. American Counselor,1.(1), 6-14 
Sue, D. W. (1990). Counseling the culturally different. New York: Wiley.

Szapocznik, J., \& Kurtines, W. (1980). Acculturation, biculturalism and adjustment among Cuban Americans. In A. Padilla (Ed.), Acculturation: Theory, models, and some new findings. Boulder, CO. Westview.

Task Force to Promote Self-Esteem and Personal and Social Responsibility (1990). Toward a state of self-esteem. Sacramento: California State Department of Education.

Tajfel, H. (1981). Human groups and social categories. New York: Cambridge University Press.

Tellez, K., \& Walker de Felix, J. Are dropout really dropouts? Paper presented at the annual meeting of the American educational Research Association. Atlanta, GA.

Toffoli, G., \& Allan, J. (1992). Group guidance for English as a second language students. The School Counselor, 40, 136-145.

Triandis, H., Lisansky, J., Setiadi, B., Chang, B., Marin, G., \& Betancourt, H. (1982). Stereotyping among Hispanics and Anglos: The uniformity, intensity, direction, and quality of auto and heterostereotypes. Journal of Cross-Cultural Psychology. 13, 409-426.

Tzuriel, D., \& Klein, M. M. (1977). Ego identity: Effects of ethnocentrism, ethnic identification, and cognitive complexity in Israeli, Oriental and Western ethnic groups. Psychological Reports 40, 1099-1110.

Urbanska, W. (1991). Self-esteem: The hope of the future. New Woman. 52-58. 
U. S. Department of Commerce, Bureau of the Census. (1991a). The Hispanic Population of the United States: March 1990. (Current Population Reports, Series P-25 No. 995). Washington, DC.

U.S. Government Printing Office. U. S. General Accounting Office (GAO). Hispanics' schooling: Risk factors for dropping out and barriers to resuming education. Report to congressional requesters. (1994). (ERIC Document Reproduction Service No. ED 374196.

Valdivieso, R. (1986). Must they wait another generation? Hispanics and secondary school reform. New York: Clearinghouse on Urban Education.

Valverde, S. (1987). A comparative study of Hispanic high school dropout and graduates: Why do some leave school early and some finish? Education and Urban Society, 19.(3), 320-329.

Velez, W. (1989). High school attrition among Hispanic and non-Hispanic white youths. Sociology of Education, 62, 119-133.

Walker, E. M. (1991). Changing self-esteem: The impact of self-esteem changes on at risk students' achievement. (ERIC document No. Ed 334 304).

Walz, G. (1991). Counseling to enhance self esteem. Ann Arbor, MI: The University of Michigan, ERIC Counseling and Personnel Services Clearinghouse. (ERIC Document Reproduction service No. ED 328 827).

Waggoner, D. (1991). Undereducation in America: The demography of high school dropouts. Westport, CT: Auburn House. 
Watt, D., \& Roessingh, H. (1994). ESL dropout: The myth of educational equity. Alberta Journal of Educational Equity, 40.(3), 283-296.

White, C., \& Burke, P. (1987). Ethnic role identity among Black and White college students: An interactionist approach. Sociological Perspectives, 30, 310-331.

Wiggins, J. D., \& Moody, A. H. (1987). Student evaluations of counseling programs: An added dimension. The School Counselor, 34, 353-361.

Willig, A. C., Harnisch, D. L., Hill, K. T., \& Maehr, M. L. (1983). Sociocultural and educational correlates of success-failure attributions and evaluation anxiety in the school setting for black, Hispanic, and Anglo children. American Educational Research Journal, 20, 385-410.

Wylie, V. L., \& Hunter, W. A. (1994). The dropout problem: Can schools meet the challenge? National Association of Secondary School Principals Bulletin, 74-80. 
Appendix A

An Analysis of Another Non-Study Group 


\section{An Analysis of Another Non-Study Group}

Besides the experimental and control groups of this study there were an additional six classes of English for Speakers of Other Languages (ESOL) receiving group counseling at the selected high school. These classes included ESOL levels II, III and IV. All the limited English proficient (LEP) students, Hispanic and non-Hispanic, in the six classes completed the Culture Free Self-Esteem Inventory (CFSEI) Form AD as a pre intervention measure during the first week of the second semester. Two other bilingual counselors on staff at the high school provided group counseling to these six classes once a week during the same 15 week period as in this study. Upon the completion of the 15 weeks, all the students in the six classes were administered the CFSEI-AD as a post intervention measure. Complete data on the CFSEI-AD for pre and post intervention were available for seventy students $(n=70)$ from the six classes.

\section{Analysis of Data}

A number of interesting findings not anticipated are worth reporting as they relate to this study. Analysis for the 70 students yielded contrasting data to that of the experimental group of this study. T-test for paired samples technique was applied to examine if group counseling had an effect these students' self-esteem scores. Comparison of mean scores for pretests and posttests self-esteem scores for this group are displayed in Table 12. 
Table 12

Comparison of Means on Pretest and Posttests Self-Esteem Scores for the Non-Study

Group $(n=70)$

\begin{tabular}{lcccc}
\hline & Pretest & Posttest & & \\
& $\underline{\mathrm{X}}$ & $\underline{\mathrm{X}}$ & "t" & Sig \\
\hline General & 10.03 & 11.17 & -2.90 & $* .005$ \\
Social & 5.71 & 6.25 & -2.55 & $* .013$ \\
Personal & 4.20 & 4.19 & .06 & .951 \\
Total & 19.94 & 21.61 & -2.45 & $* .017$ \\
\hline $\mathrm{p}<.05$ & & & & \\
\hline
\end{tabular}

Data analysis shows that these LEP students experienced more positive selfesteem scores after the counseling intervention. The positive changes were statistically significant for all the sections measured by the CFSEI-AD except personal self-esteem. Summary of the Non-Study Group

Findings suggest that students in the non-study group who participated in group counseling experienced statistically significant increases in self-esteem scores in three of the four measures, as compared to the experimental group of this study who experienced no significant difference in any of the self-esteem measures. These results indicate that 
the group counseling intervention had a positive effect on the general, social and total self-esteem scores of LEP students as measured by the CFSEI-AD.

In comparing the results of this group to the experimental group it is worth noting the differences and commonalities between the groups. The non-study group did not include students in ESOL level I. There were only two sections of this class level at the school and one class was part of the control group and the other was part of the experimental group. Another contrast between this group and the experimental group was that the experimental group had initial higher mean self-esteem scores in the four categories of the CFSEI-AD. The non-study group included non-Hispanic students from different native origins e.g. Chinese, Portuguese, Haitian, Vietnamese, etc.

The experimental group of this study and the non-study group had the following in common: First, they were in parallel ESOL classes, levels II, III and IV in the same school, taught by the same teachers with the same curriculum during the same period. Second, they were all LEP students receiving group counseling from a bilingual counselor. Third, they were all enrolled during the second semester at the time of the pretest and posttest assessment of this study. Lastly, the non-study group and the experimental group both had lower personal self-esteem scores after the treatment. 
Appendix B

Culture Free Self-Esteem Inventory Form AD 


\section{DIRECTIONS:}

(THIS IS NOT A TEST, AND THERE ARE NO "RIGHT" OR "WRONG" ANSWERS.) Please mark each statement in the following way. If the statement describes how you usually feel, make a check mark ( ) in the "YES" column. I the statement does not describe how you usually feel, make a check mark ( ) in the "NO" column. Please check only one column (either "YES" or "NO") for each of the 30 statements.

1. Do you have only a few friends.

2. Are you happy most of the time?

3. Can you do most things as well as others?

4. Do you like everyone you know?

5. Do you spend most of your free time alone?

6. Do you like being a male?/Do you like being a female?

7. Do most people you know like you?

8. Are you usually successful when you attempt important tasks or assignments?

9. Have you ever taken anything that did not belong to you? . .

10. Are you as intelligent as most people?

11. Do you feel you are as important as most people?

12. Are you easily depressed?

13. Would you change many things about yourself if you could?

14. Do you always tell the truth?

15. Are you as nice looking as most people?

16. Do many people dislike you?

17. Are you usually tense or anxious? . . . . . . . . . .

18. Are you lacking in self-confidence?

19. Do you gossip at time? . . . . . . . . . . . . . .

20. Do you often feel that you are no good at all?.........

21. Are you as strong and healthy as most people?

22. Are you feelings easily hurt? .

23. Is it difficult for you to express your views or feeling? ....

24. Do you ever get angry?

25. Do you often feel ashamed of yourself? ...........

26. Are other people generally more successful than you are? . .

27. Do you feel uneasy much of the time without knowing why?

28. Would you like to be as happy as others appear to be?....

29. Are you ever shy? . . . . . . . . . . . . . . .

30. Are you a failure?

31. Do people like your ideas?

32. It is hard for you to meet new people?

33. Do you ever lie?

34. Are you often upset about something?

35. Do most people respect your views?

36. Are you more sensitive than most people?

37. Are you as happy as most people?

38. Are you ever sad?

39. Are you definitely lacking in initiative?

40. Do you worry a lot? 
Nombre Edad Fecha de Nacimiento

Examinador/a.

Fecha de Hoy

Puntaje $G$ P

\section{Instrucciones}

Por favor, llene el cuestionario de la siguiente manera. Si la pregunta corresponde a lo que Ud. siente o piensa generalmente, marque una cruz $(\downarrow)$ en la columna que dice " $\$ 1$." Si la pregunta no corresponde a lo que Ud. siente o piensa generalmente, marque una cruz $(\checkmark)$ en la columna que dice "no." Por favor, marque una sola de las columnas (o la que dice "si" o la que dice "no," y no ambas) para cada una de las 40 preguntas. Este no es un examen y ninguna respuesta es ni "acertada" ni "equivocada."

1. ¿ ¿ Tiene usted solamente unos pocos amigos?

2. ¿ Está usted feliz la mayor parte del tiempo?

3. ¿ Puede usted hacer la mayor parte de las cosas tan bien como los demas?

4. ¿ Le gusta a usted toda la gente que conoce?.

5. ¿ Pasa usted la mayor parte de su tiempo libre a solas?

6. ¿ Le gusta a usted ser varon/mujer?

7. ¿ Cree que usted le gusta a la mayor parte de la gente?

8. Generalmente, $i$ tiene usted éxito cuando trata de hacer tareas o proyectos importantes?

9. ¿ $\mathrm{Ha}$ robado usted alguna vez?

10. $i$ Es usted tan inteligente como la mayor parte de la gente?

11. ¿Le parece que usted es tan importante como la mayor parte de la gente?

12. ¿ Se ueprine usieủ fácinende?

13. ¿ Trataría usted de ser muy diferente si pudiera?

14. ¿ Dice usted la verdad siempre?

15. ¿ Es usted tan bien parecido/a como la mayor parte de la gente?

16. ¿Cree que usted no les gusta a muchas personas?

17. Generalmente, ¿ estrasted tenso/a o nervioso/a.

18. ¿ Le falta a usted la confianza en $s i$ mismo/a?

19. ¿ Chismea usted a veces?

20. ¿ Tiene usted la impresión muchas veces de que usted no vale nada en absoluto?

21. ¿Es usted tan fuerte y sano/a como la mayor parte de la gente?

22. ¿ Se ofende usted facilmente?

23. ¿ Le resulta a usted diffcil expresar sus opiniones o abrirse a los demás?

24. i Se enoja usted a veces? .

25. ¿ Se siente usted muchas veces avergonzado/a de si mismo/a?

26. En general, ¿ tienen los otros mas Exito que usted?

27. ¿ Se siente usted inseguro/a muy a menudo sin saber por qué?

28. ¿ Le gustaría a usted ser tan feliz como parecen ser los demás?.

29. ¿ Es usted tímido/a a veces?

30. ¿ Es usted un fracaso?

31. $i$ Cree usted que sus ideas le gustan a la gente?

32. 6 Le resulta dificil a usted conocer a nuevas personas?

33. ¿ Miente usted a veces?

34. ¿ Se siente usted trastornado/a muchas veces?

35. ¿ Cree usted que la mayor parte de la gente respeta sus opiniones?

36. ¿Es usted más sensible que la mayor parte de la gente?

37. ¿ Es usted tan feliz como la mayor parte de la gente?

38. ¿ Estr usted triste a veces?

39. ¿Cree usted que realmente le falta iniciativa?

40. ¿ Se preocupa usted mucho?

Copyright $\odot 1981$, by Special Child Publications. All rights reserved. Reorder from: Special Child Publications, 4535 Union Bay Place NF. Seattle, Washington 98105. 
Appendix C

Short Acculturation Scale for Hispanic Youth 
Nombre

Fecha

\section{SASH-Y}

1. Cual idioma puede usted leer y hablar?

(a) solamente Espanol

(b) Espanol mejor que Ingles

(c) !os dos iguales

(d) Ingles mejor que Espanol

(e) solamente Ingles

2. En cual idioma le hablan sus padres a usted?

$\begin{array}{ll}\text { (a) solamente Espanol } & \text { (c) los dos iguales }\end{array}$

$\begin{array}{ll}\text { (b) mas Espanol que Ingles } & \text { (d) mas Ingles que Espanol }\end{array}$

(e) solamente Ingles

3. Cual idioma habla usted usualmente en su casa?

(a) solamente Espanol

(c) los dos iguales

(b) mas Espanol que Ingles

(d) mas Ingles que Espanol

(e) solamente Ingles

4. En cual idioma piensa usted usualmente?
(a) solamente Espanol
(c) los dos iguales
(b) mas Espanol que Ingles
(d) mas Ingles que Espanol

(e) solamente Ingles

5. Cual idioma habla usted con sus amistades usualmente?
(a) solamente Espanol
(c) los dos iguales

(b) mas Espanol que Ingles

(d) mas Ingles que Espanol

(e) solamente Ingles

6. En cual idioma son los programas de television que usted mira?
(a) solamente Espanol
(c) los dos iguales
(b) mas Espanol que Ingles
(d) mas Ingles que Espanol

(e) solamente ingles

7. En cual idioma son los programas de radio que usted escucha?

(a) solamente Espanol

(c) los dos iguales

(b) mas Espanol que Ingles

(d) mas Ingles que Espanol

(e) solamente Ingles 
8. En cual idioma son los cines y los programas de television y radio que usted prefiere mirar y escuchar?
(a) solamente Espanol
(c) los dos iguales
(b) mas Espanol que Ingles
(d) mas Ingles que Espanol

(e) solamente Ingles

9. En cual idioma hablan tus padres con sus padres?
(a) solamente Espanol
(c) los dos iguales
(b) mas Espanol que Ingles
(d) mas Ingles que Espanol

(e) solamente Ingles

10. Las amistades mas cercanas que usted tiene son:
(a) todas Hispanas
(b) mas Hispanas que norteamericanas
(c) mitad Hispanas y mitad norteamericanas
(d) mas norteamericanas que Hispanas
(e) todas norteamericanas

11. Prefiere ir a fiestas donde las personas son:
(a) todas Hispanas
(b) mas Hispanas que norteamericanas
(c) mitad Hispanas y mitad norteamericanas
(d) mas norteamericanas que Hispanas
(e) todas norteamericanas

12. Las personas que visitas o te visitan son:
(a) todas Hispanas
(b) mas Hispanas que norteamericanas
(c) mitad Hispanas y mitad norteamericanas
(d) mas norteamericanas que Hispanas
(e) todas norteamericanas 
1. What languages do you read and speak?
(a) Spanish only
(b) Spanish better than English
(c) both equally
(d) English better than Spanish
(e) English only

2. What languages do your parents speak to to you in?
(a) Spanish only
(b) Spainsh better than English
(c) both equally
(d) English better than Spanish

(e) English only

3. What languages do you usually speak at home?
(a) Spanish only
(b) Spanish better than English
(c) both equally
(d) English better than Spanish

(e) English only

4. In which languages do you usually think?
(a) Snenish onlv
(b) Spanish better than English
(c) both ecually
(d) English better than Spanish

(e) English only

5. What languages do you usually speak with your friends?
(a) Spanish only
(b) Spanish better than English
(c) both equally
(d) English better than Spanish

(e) English only

6. In what languages are the T.V. programs you usually watch?
(a) Spanish only
(c) both equally
(b) Spanish better than English
(d) English better than Spanish

(e) English only

7. In what languages are the radio programs you usully listen to?

(a) Spanish only

(b) Spanish better than English

(e) English only (c) both equally

(d) English better than Spanish

8. In what languages are the T.V., movies, and radio prorams you prefer to watch or listen to?

(a) Spanish only

(b) Spanish better than English

(e) English only (c) both equally

(d) English better than Spanish 
9. In what languages do your parents speak with their parents?
(a) Spanish only
(c) both equally
(b) Spanish better than English
(d) English better than Spanish

o

(e) English only

10. Your close friends are:
(a) all Hispanics
(b) more Hispanic than Americans
(c) half Hispanics and half American
(d) more Americans than Hispanics
(e) all Americans

11. You prefer going to parties at which the people are:
(a) all Hispanic
(b) more Hispanic than American
(c) half American and half Hispanic
(d) more Americans than Hispanics
(e) all Americans

12. The persons you visit or who visit you are:
(a) all Hispanic
(b) more Hispanic than American
(c) half Hispanic and half American
(d) more Hispanic than Americans
(e) all Americans 
Appendix D

Background Information Questionnaire 
Sex: Male

Age: Female

Place of Birth:

Number of people living at home:

Race and/or Ethnic Group: Black

Native American

Asian-American

White

Hispanic Grade

learn to speak:

What language did you first l
Mother's current occupation:

Father's current occupation:

Length of Residence in the United States: years months

ESOL class level:

Mother's Education: Less than elementary

High school

Elementary

College degree Specify ethnic group

\section{College degree}

Father's Education: Less than elementary High school

College degree Some College Graduate degree

Elementary

Some College

Graduate degree

Reduced or Free Lunch: Yes

$$
\text { No }
$$

In my country my mother's occupation was:

In my country my father's occupation was:

What is your favorite subject in high school?

What is your least favorite subject in high school?

How would you describe your relationship with teachers?

Very good Good Fair Poor

How would you describe your relationship with administrators--principal--vice principals?

Very good Good Fair Do you know who your counselor is? Yes How many times have you seen your counselor this year?
o times 1-2 times 3-4 times Poor No How many times are you absent?

1-2 days a semester 1-2 days a month pass on your first report card this year? How man All 5 4 3 1 None 
Appendix E

Sample Lessons 
Exercise 4

THE GARBAGE PAIL

Purpose:

1. To encourage empathy through identification with the feelings of others.

2. To present risk-taking through revealing negative aspects of a person's own life.

3. To recognize common themes in order to illustrate that many problems are universal.

Materials:

One photocopy of the illustration for each member; crayons or markers.

Description:

A. The group leader holds up the illustration and asks the group what they think the garbage pail symbolizes. The leader directs the discussion towards a focus on having the opportunity to throw something out of their lives.

B. While handing out the materials, the leader tells members to imagine discarding something. This may be a person, an object, a place, or a feeling.

C. They are told to illustrate this as if it were being dropped from the hand to the wastebasket.

\section{Group Discussion:}

Members describe the negative aspects of their lives as presented in their illustrations. The group explores individual choices through comments and questions. The leader helps the group to identify feelings and common themes. Some people will identify tangible disappointments, such as a useless gift. Others will describe abstract concepts such as entering a poor relationship.

Leaders may often find that members discard the negative aspects of the environment in which they are living. This is especially true for inpatient or residential facilities. This exercise works well with almost any group type in any stage of development because of its wide range of acceptable responses (person, object, place, or feeling). In addition, it may be useful in acquainting new members with one another in the early stage of group development.

\section{Variation:}

The sheet is turned upside-down as if something were being dropped from the basket in to the hand. The exercise would focus on describing something (person, object, place, or feeling) members would like to retrieve which they had discarded in the past.

Copyright 1988 by the Professional Resource Exchange, Inc. 


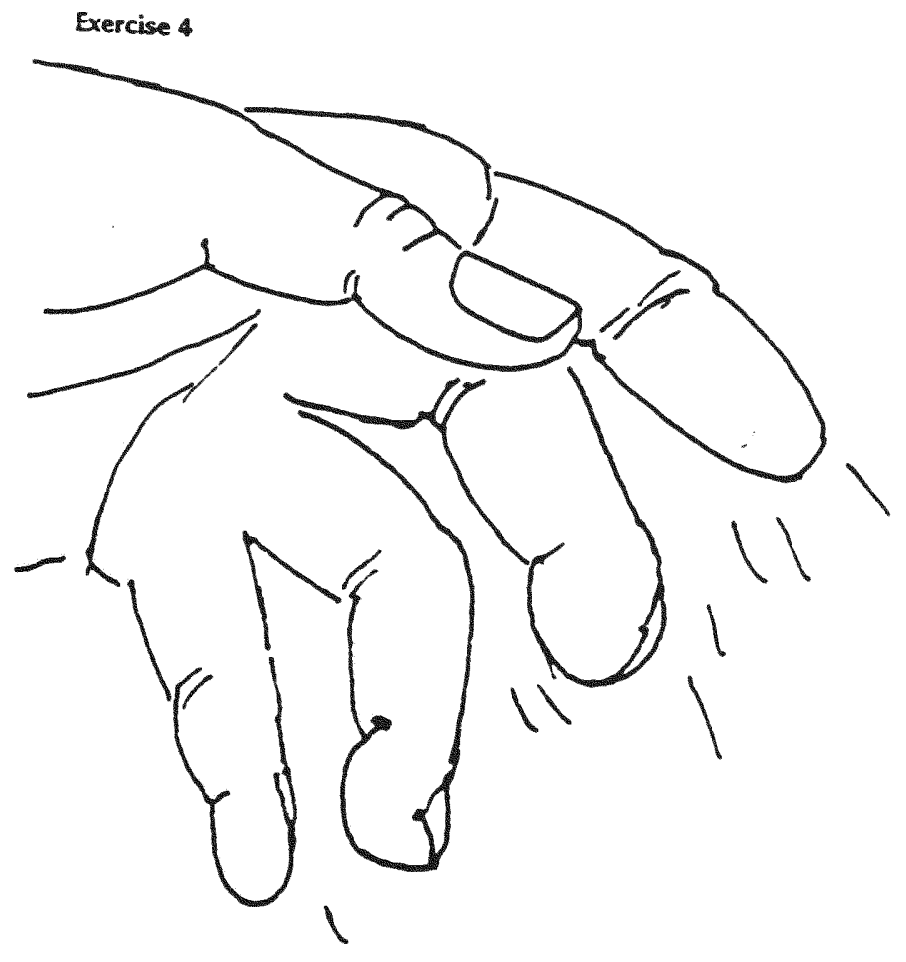


Exercise 25

\section{THE BLANK CHECK}

Purpose:

1. To provide an opportunity for open communication in order to identify topics of concern.

2. To recognize and understand each other's needs.

3. To promote group identity and cohesion by bonding together and being supportive of one another.

Materials:

One photocopy of the illustration for each group member; crayons or markers.

\section{Description:}

A. The leader holds up the picture of a blank check and asks how it might relate to a common fantasy.

B. Each participant is given the illustration of the blank check.

C. Group members fill in their own names (pay to ), an emotional need (for feeling solve this need. , and the dollar amount they would spend to re-

D. The papers are collected, and then re-distributed so that each member gets someone else's check.

E. Upon reading the check received, members draw in a practical suggestion of how they would fill that person's emotional need.

F. The completed check is returned to the member whose name is on it.

\section{Group Discussion:}

Members identify topics of concern by revealing to the entire group the personal need addressed on the check. The group leader encourages other members to explore the importance of each member's need. In addition, the members discuss whether they can help meet each other's needs as a group.

The idea of a check of ten leads members to think of material needs. The group leader reminds members to think about emotional needs. This exercise can be done with a variety of groups beyond the early stage of development.

\section{Variation:}

The leader puts each member's name on a separate blank check. These are distributed at random. Each member thinks of an item needed by that person, draws it in, and writes an amount on the check.

Copyright 1988 by the Professional Resource Exchange, Ine. 
Exercise 25

$708-876-0087 /-22$

NO. 555

DATE

19

PAY TO

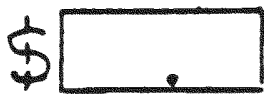

AMOUNT

AHE UNITED
ES. STATES BANK

FOR FEELING 


\section{Worksheet \\ HOW DO YOU FEEL?}

\section{This is all about:}

Helping you understand your emotional reactions to different situations.

\section{What you will do:}

1. Complete the open-ended sentences below.

2. As a class, discuss the two questions at the bottom of the page.

\section{Sentences to Complete:}

1. When I'm proud of myself, I

2. I love

3. I am afraid of

4. I'm embarrassed when

5. I hate

6. I want to be

7. I am happiest when

8. I am worried about

9. In my free time, I like to

10. Someone who means the most to me is

11. In school, I do best when

12. I need to work harder in

\section{Questions:}

As a class, discuss:

1. What did you find out about yourself?

2. What do you need to do more of to feel good about yourself?

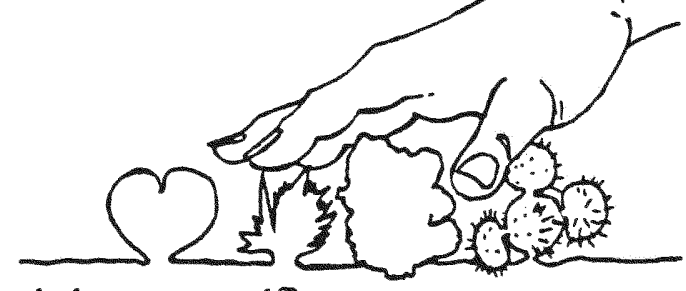




\section{Learning Objective:}

To learn to write affirmations to improve self-concept.

\section{Procedure:}

1. Deine the term affirmation for the students. An affirmation is a positive statement we tell ourselves about the achievement of our goals.

A. Affirmations are: positive

personal

specific

in the present tense

B. Affirmations are word tools we use to reach goals.

2. Demonstrate how affirmations are written.

A. Choose a goal: for example, improving an English grade.

B. Nake it specific and positive: raise that grade from $C$ to $B$.

C. Write it in the present tense: I am proud that I am earning a $B$ grade in English.

3. Have students choose three goals: one personal, one school-related, and one home/family-related.

4. Have students write a positive affirmation for each goal.

5. Say, "See yourself accomplishing your goals. Close your eyes. In your mind's eye visualize the personal, school, and family goals you wrote as affirmations happening to you." 


\section{Worksheet \\ MY PLUSES AND MINUSES}

This is all about:

Helping you identify positive and negative traits.

\section{What you will do:}

1. Check off the words below that describe you.

2. As a class, discuss whether these words are positive or negative. Does everyone in the class agree?

\section{List:}

\begin{tabular}{ll} 
h happy & nervous \\
slow & calm \\
smart & sood \\
dumb & fuccessful \\
funny & failure \\
shy & brave \\
friendly & lonely \\
good student & generous \\
sad & jealous \\
kind & comfortable \\
strong & guilty \\
weak & alone \\
lazy & well-liked \\
ugly & too thin \\
handsome & beautiful \\
worried & nice \\
clumsy & angry \\
\hline
\end{tabular}

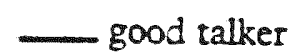

- good writer

- quiet

_ intelligent

bored

- fearful

- healthy

sick

- different

- accepted

_- good-looking dull talented interested responsible hard worker too fat

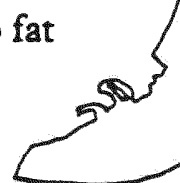

How many items checked above would you rate as:

Positive attitudes ?

Negative attitudes ? 


\section{Worksheet \\ PLUSES INTO ACTION}

This is all about:

Lcarning to write and use affirmation statements.

\section{What you will do:}

1. In each of the following three categories, think of two traits about which you feel good and about which you are proud.

2. Using each trait, write affirmations for each category in the following manner:

\section{Self}

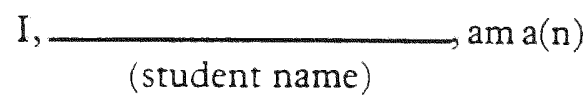

(adjective)

(noun)

$I, \longrightarrow$ am a(n)

\section{Schoolwork}

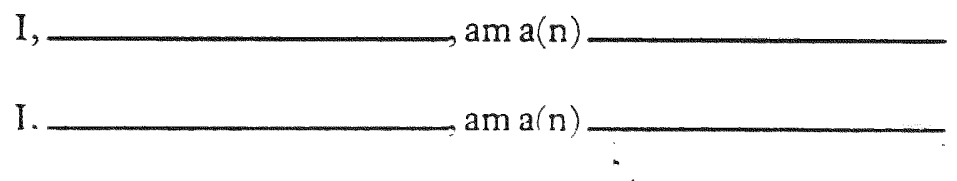

\section{Others}

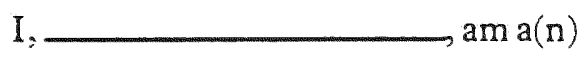

$I, \longrightarrow a m a(n)$

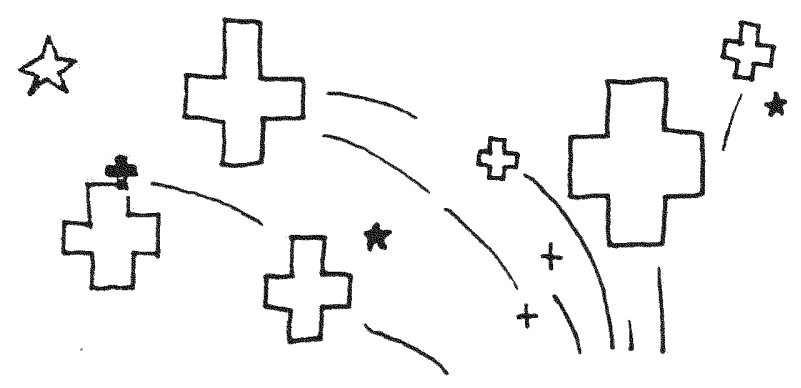

(c) $1988 \mathrm{~J}$. Weston Waich, Publisher

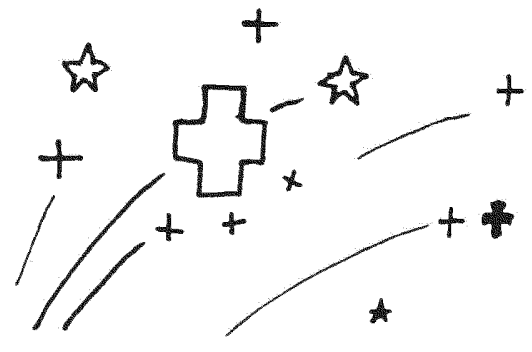

Building a Positive Self-Concept 


\section{Worksheet \\ I SEE ME, YOU SEE ME ...}

This is all about:

Helping you become more aware of how you see yourself.

\section{What you will do:}

1. Fill in the "mirrors" on this worksheet using words, phrases, or drawings that describe how you think you are viewed by others.

2. Take five minutes to write a letter to yourself on one of the following topics:

A. How do you feel about how you see yourself?

B. How do you feel about how others see you?

C. To make others see you differently, what would you change? How would you do it?

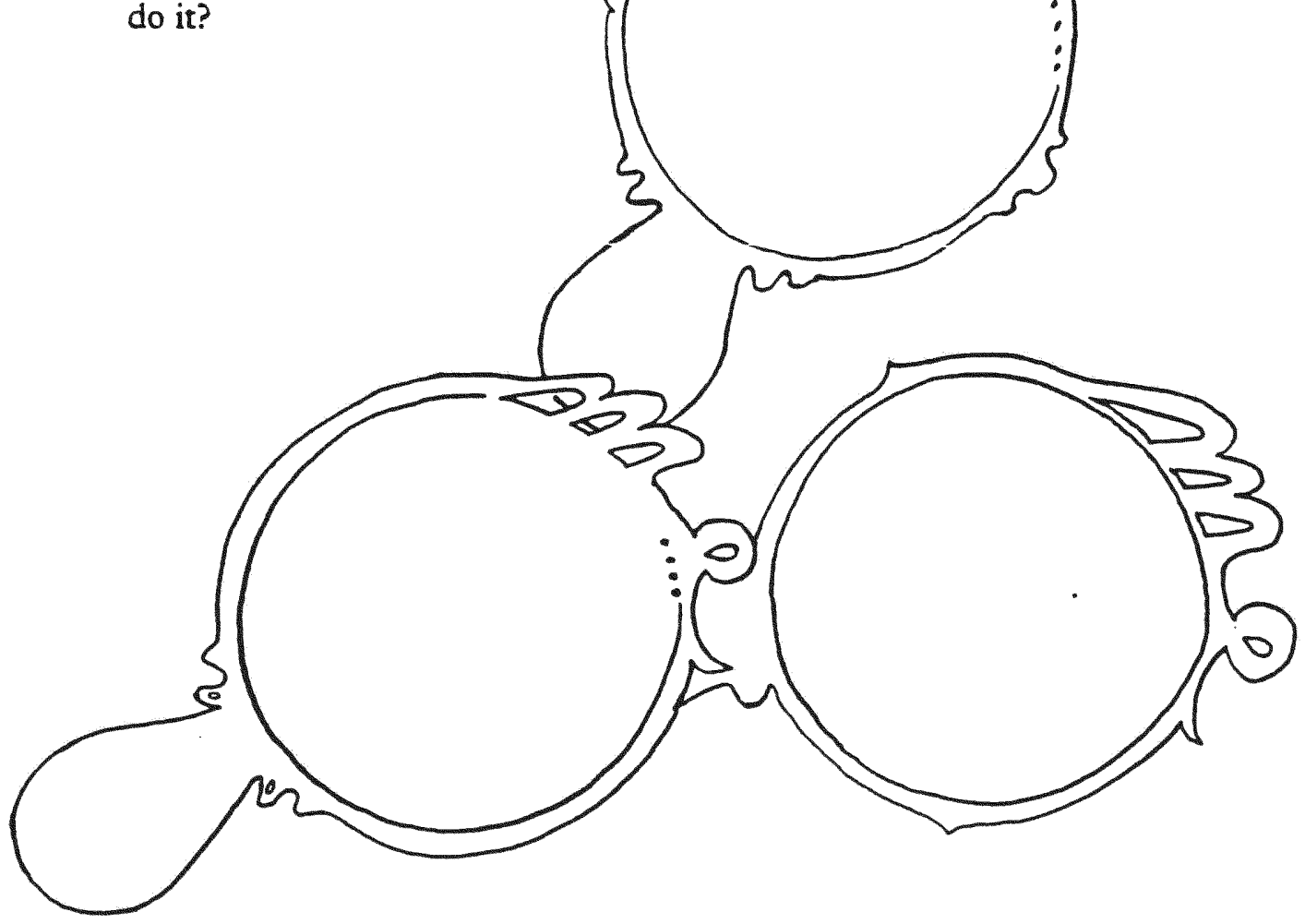


December 9, 1949

1971

1971-1973

1975

1973-1976

1976-1978

1978-1980

1986-1989

1989

1989-1994
Born, Havana, Cuba

B.A., Education

University of Miami

Miami, Florida

Social Worker

Department of health and Rehabilitative Services

Miami, Florida

M.S., Early Childhood Education

Florida International University

Miami, Florida

Kindergarten Teacher

Miami Heights Elementary School

Miami, Florida

Project Director

Little Havana Activities Center

Miami, Florida

Legislative Assistant

Florida House of Representatives

E.S.O.L. Teacher

Calusa Elementary

Miami, Florida

Counseling Certificate Programs

Florida International University

Miami, Florida

Counselor

Miami Sunset Senior High School

Miami, Florida 
1991-1993

Adjunct Professor

Florida International University

Miami, Florida

1994-1996

Dean of Students

Miami Sunset Senior High School

Miami, Florida

\section{PUBLICATIONS AND PRESENTATIONS}

Covert, Y. A. and Gutierrez, S. (April, 1990). The long-term impact of Bilingual/ESL Inservice Workshops. Paper presented at the meeting of the National Association of Bilingual Education, Tucson, Arizona. 